\title{
A Cognitive-Ecological Approach to Preventing Aggression in Urban Settings: Initial Outcomes for High-Risk Children
}

\author{
Metropolitan Area Child Study Research Group
}

\begin{abstract}
A multiyear, multicontext aggression prevention intervention was provided during the early or late elementary school years in an inner-city and an urban poor community. Sixteen schools were randomly assigned to 1 of 4 conditions: (a) no-treatment control, (b) general enhancement classroom program, (c) general enhancement plus small-group peer-skills training, or (d) general enhancement plus small-group peer-skills training plus family intervention. This article reports on results for the high-risk subsample of 1,500 children. Results from hierarchical linear modeling indicate that comprehensive interventions, if provided in early grades, can be effective for children in schools in settings with resources adequate to support learning and development, but some unintended effects can occur in schools in the most distressed communities when delivered too late in development.
\end{abstract}

In response to increasing rates of serious youth violence in the United States in the late 1980s and early 1990s, there has been a surge of research to investigate strategies for preventing aggressive and antisocial behavior in adolescents. Much of the recent research has focused on evaluating large-scale preventive interventions that consider multiple influences on development across varying contexts. This is particularly important given the limited effectiveness of single-component or single-context interventions (Kazdin, 1987; Tolan \& Guerra, 1994). Furthermore, because of the disproportionate concentration of serious youth violence in urban communities characterized by more extreme and persistent environmental stressors (e.g., scarce economic, health, and educational resources; unemployment; and neighborhood violence), there has been a growing concern that programs be developed and tested in such settings. The present study provides preliminary outcome data from one of these efforts: the Metropolitan Area Child Study (MACS). The MACS is an 8-year prevention research trial targeting elementary school children from inner-city and urban communities (Guerra et al., 1993). The long-term goal of the intervention is to reduce violent behavior. However, because serious youth violence typically does not emerge until adolescence, our shortterm focus was to promote protective factors, such as school achievement, and to reduce aggression to decrease risk for later violence. This strategy is consistent with prediction studies, which indicate that early aggressive behavior is among the best predictors of later criminality and violence (Eron, 1987; Huesmann, Eron,

The Metropolitan Area Child Study Research Group is a collaboration of Leonard Eron, Rowell Huesmann, and Anja Spindler, Department of Psychology, University of Michigan; Nancy Guerra, Department of Psychology, University of California, Riverside; David Henry and Patrick Tolan, Department of Psychiatry, University of Illinois at Chicago; Rick VanAcker, Department of Psychology, University of Illinois at Chicago.

This work was supported by grants from the National Institute of Mental Health and the Centers for Disease Control and Prevention.

Correspondence concerning this article should be addressed to Patrick Tolan, Department of Psychiatry, Institute for Juvenile Research, University of Illinois, 840 South Wood Street, Chicago, Illinois 60612-7347. E-mail: Tolan@uic.edu
Lefkowitz, \& Walder, 1984). Similarly, interventions that promote protective factors have demonstrated preventive benefits (Conduct Problems Prevention Research Group, 1999; Grossman et al., 1997; Hawkins, Von Cleve, \& Catalano, 1991; Pepler, King, \& Byrd, 1991).

In recent years, research on aggression and youth violence has undergone two important shifts. First, there has been a growing interest in the social-cognitive underpinnings of aggression, including social information-processing skills, specific beliefs, and cognitive scripts (Crick \& Dodge, 1994; Huesmann, 1988, 1998). Second, there has been an increasing attempt to understand the influence of multiple contexts (e.g., schools, peers, and families) in the learning and continuation of aggression, including how such behavior is influenced by specific relationships and social interaction patterns in these contexts (Henggeler et al., 1986; Tolan, Guerra, \& Kendall, 1995; Weissberg \& Greenberg, 1997). In the MACS, our preventive intervention is directed at modifying both individual social-cognitive and contextual factors relevant to the learning of aggression. We called this approach a cognitiveecological model (Guerra, Eron, Huesmann, Tolan, \& VanAcker, 1997).

An important, but principally unanswered, question is how much intervention, at what age, and in which contexts is necessary to prevent or mitigate aggression and violence among children most at risk. To address this question, we evaluated, at two grade levels, the effectiveness of three intervention conditions. These conditions represented increases in the number of contexts involved and in the dose received through this cognitive-ecological model. To the extent that aggression is learned and reinforced across multiple contexts, intervention effectiveness for those most at risk should increase as the number of targeted contexts increases. This study thus adds to the existing literature by (a) testing the efficacy of multiple levels of intervention in impoverished urban communities, (b) comparing the efficacy by community type, (c) comparing the efficacy relation to timing of intervention, and (d) evaluating the impact on two important risk factorsaggression and academic achievement. Also because this study includes an ethnically diverse sample with both genders well represented, it permits consideration of the variation in impact. 
We began with the most cost-effective and least intrusive method of intervention, a 2-year program providing teacher consultation and a 40-lesson, social-cognitive curriculum (Yes I Can) delivered to all children in the classroom. Teacher consultation focused primarily on classroom management, encouraging prosocial behavior in the classroom, and cultural competency training. The Yes I Can curriculum covered five areas of social cognition, each related to risk for aggression: self-understanding/selfefficacy, social perspective taking, normative beliefs about aggression, social problem-solving skills, and behavioral scripts. This intervention condition is labeled the general enhancement classroom intervention, or Level A intervention. Recent findings from similar large-scale projects suggest that interventions of this type have a significant impact on reducing children's aggression and enhancing protective factors during the early elementary school years. For example, the Conduct Problems Prevention Research Group (1999) reported decreases in aggression and increases in achievement-related outcomes, such as on-task behavior, in firstgrade classrooms using the PATHS (Promoting Alternative Thinking $\underline{\text { Strategies}) ~ c u r r i c u l u m ~(G r e e n b e r g, ~ K u s c h e, ~ C o o k, ~ \& ~ Q u a m m a, ~}$ 1995) and teacher consultation. Similar interventions delivered as early as kindergarten have both decreased aggression and increased achievement, immediately on program completion as well as several years later (Kellam, Rebok, Ialongo, \& Mayer, 1994). Notably, although these programs were delivered to all children, regardless of risk, it is common to find that effects are "concentrated" or not uniform across risk levels (Olds, 1990; Reid, Eddy, Fetrow, \& Stoolmiller, 1999).

Nevertheless, although some universal interventions appear to have a significant preventive benefit for all participants, there is reason to believe that more aggressive or at-risk children probably need more extensive interventions to benefit. Indeed, we expected that outcomes for high-risk youths would be enhanced if skills and competencies addressed in the general classroom intervention were also modeled and reinforced across different socialization contexts. Given the increasing salience of the peer group as an intervention context during the school years, the next level of intervention provided a 2-year, small-group training for high-risk children in addition to the general enhancement program (Eargle, Guerra, \& Tolan, 1994). We labeled this intervention condition the general enhancement plus small-group peer-skills training, or Level B intervention. The Level B intervention was designed to change cognitions and behavior among the high-risk group, as well as to minimize peer reinforcement of aggression by changing peer group norms on behavioral standards. As previous studies have shown, when aggressive and deviant behaviors are actively reinforced by peers, such behaviors are likely to increase (Dishion, Spracklen, Andrews, \& Patterson, 1996; Elliott, Huizinga, \& Ageton, 1985; Henry et al., 2000). Thus, changing the norms and behaviors of a smaller group of high-risk children should provide an additive effect beyond that of the general enhancement intervention.

The third and most comprehensive intervention conditionLevel C intervention-added a 1-year family intervention for high-risk children and their families. We labeled this the general enhancement plus small-group peer-skills training plus family intervention. Interventions that mobilize parents and provide family support have been shown to reduce aggression and delinquency from early childhood (e.g., Webster-Stratton, 1990) to adolescence (e.g., Chamberlain \& Moore, 1998; Henggeler, Cunningham, Pickrel, Schoenwald, \& Brondino, 1996). Similarly, interventions that combine peer training and family interventions have been shown to reduce antisocial behavior and increase school success for younger elementary school-age children (McCord, Tremblay, Vitaro, \& Desmarais-Gervais, 1994). Family intervention may counteract negative effects found in some small-group interventions (Dishion, McCord, \& Poulin, 1999). For this reason, it may be necessary to combine peer training with family intervention to teach effective parenting skills and provide a support network for parents of high-risk children. The family intervention used in the present research was designed to help parents recognize and reinforce prosocial behavior, improve parenting skills such as monitoring children's peers, enhance family communication, and provide an opportunity for family support (Tolan \& McKay, 1996).

In addition to basic efficacy, we were interested in the role of developmental timing on intervention outcomes. To examine this, we provided the intervention to some cohorts during the early elementary years (Grades 2-3), to some during the late elementary years (Grades 5-6), and to some during both periods. The targeted constructs were the same for both ages, with changes made in content and format (e.g., reading level) to ensure developmental appropriateness. Within the field of prevention, integrating developmental theory and prevention science has generated much interest (Coie et al., 1993; Weissberg \& Greenberg, 1997). Perhaps the most notable recent trend has been to begin interventions as early as possible. The "earlier is better" dictum has been bolstered by comprehensive reviews showing that programs beginning as early as preschool can have a long-term impact on delinquency prevention (Yoshikawa, 1994; Zigler, Taussig, \& Black, 1992). Indeed, many effective school-based interventions have been delivered during the early grades (e.g., Conduct Problems Prevention Research Group, 1999; Kellam et al., 1994). A focus on early development is also consistent with recent neuroscience studies that have shown an increase in synaptic connections until about age 10, when connections begin to die out (Shair, 1991). It is also consistent with studies that have shown that aggression is stable from the early elementary school years (Huesmann et al., 1984) and findings that the role of social-cognitive factors appears to crystallize during the later elementary years (Huesmann \& Guerra, 1997). Thus, we expected that the early intervention would have a greater impact than the later intervention on aggression.

We were also concerned about the influence of community contexts and school resources on intervention effects. There is substantial evidence that many preventive interventions do not work equally well in all settings or have the same impact on all participants (Olds, 1990; Rubin, Bream, \& Rose-Krasnor, 1991; Weissberg et al., 1981). As Brown (1993) noted, a fundamental task of the prevention research is to examine how efficacy varies as a function of environmental or participant characteristics. Within urban schools and communities, there is considerable variation in resources available and social organization (Greenwald, Hedges, \& Laine, 1996). One of the defining distinctions of the inner city is that schools and other social institutions face extreme economic and social strain, compared with other urban schools (McLoyd, 1990; Wilson, 1987). These schools may be less effective because of these limitations. For example, in our study, inner-city schools were typically understaffed, used older and less plentiful books, and had lower levels of teacher stability than did 
the other urban schools. In addition, the inner-city schools served communities facing more extreme and more prevalent social stress levels (Guerra, Huesmann, Tolan, VanAcker, \& Eron, 1995). The ecology of high need and limited resources can be characterized as impeding schools' abilities to educate and socialize children.

Although the need for preventive interventions may be greater in neighborhoods with greater economic disadvantage and social disorganization, these circumstances may also make it more difficult for interventions to have a significant impact than would be the case in less distressed areas. In fact, several evaluations of preventive interventions have demonstrated poorer outcomes in very disadvantaged schools and communities (Aber, Jones, Brown, Chaudry, \& Samples, 1996; Weissberg et al., 1981).

Although our primary outcome of interest was children's aggressive behavior, we were also interested in examining the intervention impact on positive behaviors that might serve as protective factors. We therefore included assessments of academic achievement. Many of the consultation and curriculum activities in the general enhancement program were presented as aids to improve children's academic achievement. For instance, we provided direct links to reading and math for many of the Yes I Can lessons. This integrated the social-cognitive tasks of the Yes I Can program into other areas of study and across the school day. We also hoped that a focus on academic achievement would increase teacher participation and interest in the program. Further, we expected that improving academic achievement should result in corresponding decreases in aggression, either concurrently or in the future, given the rather robust negative relation between academic achievement and aggression (Gottfredson, 1987; Huesmann, Eron, \& Yarmel, 1987).

Thus, the present research provides an opportunity to address several prevention issues simultaneously. First, we examine whether a 2-year "universal" intervention (given to all, regardless of risk) can prevent aggression and achievement among high-risk children. Second, we assess whether the effects of this general enhancement program are enhanced by adding a small-group peertraining program and a small-group program plus a family intervention. This can help determine whether the added costs and burdens of selective interventions are justified. Third, we compare effects of interventions conducted at two different times in the elementary years. The early intervention was conducted when the children were in Grades 2 and 3, and the late intervention was conducted when children were in Grades 5 and 6 . Fourth, by comparing two poor urban communities, we examine the extent to which community and school conditions moderate intervention impact. This article focuses on these issues and effects for only the high-risk subsample in each condition.

Specifically, we hypothesized that the general enhancement classroom intervention would result in increases in academic achievement for high-risk children compared with a control group but that it would require additional interventions focused on peerskills training and peer-skills plus family intervention to affect aggression. Further, we hypothesized that these effects would be stronger for younger children and for children in communities with less impoverished conditions. Given that most previous prevention research of this type has focused on boys and little is known about the effectiveness of interventions with girls, no specific predictions for different effects by gender were made.

\section{Method}

To test these hypotheses, we conducted a longitudinal, quasiexperimental field study that spanned 8 years and included eight birth cohorts of children. We began with a true experimental design in which each of 16 schools was randomly assigned to one of the four conditions (three treatment groups and one control). The design is shown in Figure 1. Four schools received the general enhancement classroom intervention (labeled Level A condition). This means all children were included in general enhancement regardless of risk (although this article only focuses on the high-risk children in each condition). High-risk children in the four Level B schools were assigned to receive a combination of the classroom intervention and small-group peer-skills training. High-risk children in the four Level $\mathrm{C}$ schools were assigned to receive the combined classroom intervention, small-group peer-skills training, and the family intervention.

To test for the importance of developmental timing of interventions, we offered the intervention at two different points: Grades 2 and 3, referred to as early intervention, and Grades 5 and 6 , referred to as late intervention. Children who were in the 4th or 5th grade when the study started would only get the late intervention. Children who were in kindergarten, 1st, or 2nd grade when the study started would get both early and late interventions if they did not move out of the school. Children who entered school after the study started would only get the early intervention. If a cohort did not reach Grade 6 prior to the end of the study, they were not offered late intervention. High-risk children who were offered early and late intervention were included in the late intervention on the basis of initial risk assessment (prior to the early intervention), regardless of response to the early intervention.

We began the first preintervention assessments in spring 1991 and the first intervention in fall 1991. Interventions and assessments were provided for cohorts entering or completing an intervention each year until spring 1997. Thus, eight different cohorts of children completed at least one 2-year cycle of intervention and related assessments.

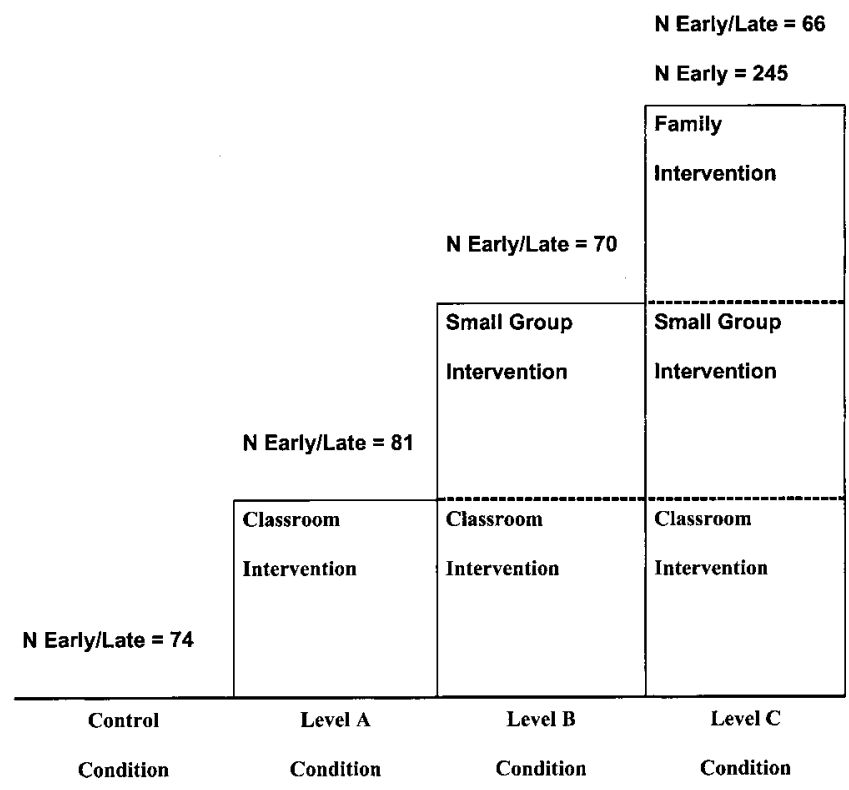

Figure 1. The design of the Metropolitan Area Child Study. Each more intensive intervention condition includes the previous intervention components. The sample sizes are the maximum number of high-risk participants who contributed data for the analysis of the specified intervention. 


\section{Participants}

This study was conducted in lower income neighborhoods of two midwestern cities in Illinois: Chicago and Aurora. Aurora is a mid-sized city located approximately 40 miles from Chicago. These two school systems were chosen to represent the "inner city" (Chicago) and "other urban poor" (Aurora) conditions as defined by Wilson (1987). Multiple indicators indicate that the Chicago schools were poorer functioning and served communities with the characteristics that Wilson used to distinguish the inner city from other urban poor communities. For example, the Chicago schools in the MACS sample had lower attendance rates (89\% vs. $94 \%$ ), higher student mobility rates (33\% vs. $28 \%$ ), and higher district high school dropout rates (17\% vs. $13 \%$ ) than the Aurora schools (Illinois State Board of Education, 1999). The Chicago schools served communities with median family incomes averaging $60 \%$ lower than the Aurora schools (U.S. Bureau of the Census, 1993). Chicago neighborhoods also had higher rates of poverty $(40.25 \%$ vs. $25.9 \%$ for Aurora), higher unemployment rates (29.4\% vs. $19.7 \%$ for Aurora), less owner-occupied housing (19.8\% vs. $57.6 \%$ for Aurora), and higher crime rates (21.94 crimes per 1,000 persons for Chicago neighborhoods vs. 11.33 per 1,000 for Aurora neighborhoods; Tolan \& Henry, 1996). The schools in Chicago were also more likely to serve large, high-rise, public housing ( 3 of 8 schools in Chicago vs. 1 of 8 in Aurora). Children from the Chicago schools reported more traumatic stressful events and chronic social and economic deprivation (Attar, Guerra, \& Tolan, 1994). Although less destitute than our inner-city Chicago neighborhoods, the Aurora schools served neighborhoods with high rates of poverty, female-headed households, and crime for urban communities. Families and schools in these other urban poor neighborhoods faced significant economic and social impediments.

We initially contacted 130 schools in these two cities that served communities with $25 \%$ or more of the student population in low-income families and $25 \%$ or more of students from minority families. Of those, 52 schools returned applications and had enrollments of fewer than 800 students (the maximum feasible for our research procedures). In Chicago, we selected 13 schools that reported $100 \%$ faculty support for participation and the research. From these, we selected four schools from predominantly African American neighborhoods on the south side of Chicago and four from more mixed-ethnicity neighborhoods on the west and north sides of Chicago. In Aurora, we selected four schools from each of the 20 eligible in their two districts. ${ }^{1}$

Because the intervention targeted children in Grades 2-3 and 5-6, our plan was to assess children when they were in the 1st (pretest), 2nd (midtest), 3rd (posttest), 4th (pretest), 5th (midtest), and 6th (posttest) grades. In the 8 years of the study, eight cohorts participated in at least two waves of assessment (pre-post); three cohorts were assessed from 1st to 3 rd grade; two from 4th to 6th grade; two in the 1st, 3rd, and 6th grade; and one in the 2nd, 4 th, and 6th grades. ${ }^{2}$ An elaborate permission procedure was used involving individual and class rewards for returning permission slips (whether or not permission was obtained).

Of the 4,471 participants with permission ( $84.2 \%$ of those solicited), 2,181 were classified as high risk based on their pretest scores on both the Peer Nominations of Aggression (Eron, Walder, \& Lefkowitz, 1971) and the Teacher's Report Form (TRF) of the Child Behavior Checklist (CBCL) Aggression scales (Achenbach, 1991). Because distributions of scores are highly skewed, we used the median and median units to determine risk status. A child's score in median units is the difference between an individual's score and the median divided by the median. Children were classified as high risk if they scored at least .5 median units above the median in the total sample or if they scored between -.5 and .5 median units of the sample median and also scored above the median for their school and grade. By way of reference to pretest level of risk, the high-risk subsamples had $52.8 \%$ of the sample scoring in the clinical range in the early treatment sample and $51.4 \%$ scoring in the clinical range in the late treatment sample. The average Peer Nominated Aggression $z$ scores were 1.19 among the early intervention sample at pretest and 0.65 among the late intervention sample at pretest. (These scores were standardized against a community sample.)

Among the high-risk sample, $60.7 \%$ were boys. The ethnic composition was $47.6 \%$ African American, 36.8\% Hispanic, and 15.5\% non-Hispanic White. Among high-risk children, rates of participation in the free-lunch program, an indicator of poverty status, ranged from $33 \%$ at one Aurora school to $100 \%$ at two Chicago schools and one Aurora school. High- and low-risk children did not differ significantly on individual eligibility for free school lunches, $t(2,331)=1.87, n s$.

Blocking and assignment of schools to conditions. To control for type of community and for average preintervention aggression levels in each condition, we blocked the 16 schools on community location and ethnicity into four groups of four schools. Each group included one school from each of the four general areas in which the schools were located (North Chicago, mixed ethnicity; South Chicago, predominantly African American; East Aurora, mixed ethnicity; and West Aurora, mixed ethnicity). All groups had comparable mean aggression levels (as assessed by Eron et al.'s, 1971, peer-nominated index of aggression administered in all grades). The blocks of schools were then randomly assigned to treatment conditions. Although the ethnic composition of our sample was diverse and is balanced by condition, ethnicity was highly confounded with school and community. Four of the Chicago schools were over 95\% African American, for example. The ethnic distributions in the Aurora schools were more even. Consequently, we were unable to separate ethnicity effects from school and community effects.

Attrition. As in any long-term intervention study, a major problem is attrition and the handling of missing data. There were two types of attrition in this study: school and individual. Schools and individuals are particularly likely to drop out in low-income neighborhoods, and attrition was indeed a problem in the present study.

Some notable changes in schools' participation occurred after the initial assignment. During the 2nd year of intervention, one South Chicago school assigned to the Level B condition withdrew from the study. After the 3rd year of intervention, the four schools in West Aurora had to be dropped from the study because a change in administration resulted in a withdrawal of support for the project. After the 4th year of the intervention, the Level C South Chicago school dropped out because teachers were no longer interested in cooperating. ${ }^{3}$ To avoid biasing our results, we used subsets of the data appropriate for testing each of our major hypotheses. We excluded data after the "dropout" from blocks that lost a school relevant to the hypothesis. For example, in testing Level B versus control, results would be biased if we used control school data from South Chicago after the Level B school from South Chicago had dropped out. However, the same would not apply to tests of our other two comparisons of interest: Level C versus the control condition and Level A versus the control condition. The dropout of a Level B school would not affect the validity of those tests. In all the analyses reported in this article, we use the subset of schools and cohorts for each hypothesis that gives us the most data to test the hypothesis in a valid, unbiased manner (i.e., as a true random assignment).

Individual participant attrition was also substantial because of the high mobility of the population. Of the original 2,181 high-risk children, 1,677

${ }^{1}$ The superintendents, school boards, and principals in Aurora participated in identifying the subsets of schools that would cooperate, and those are the ones in which the presentations were made.

${ }^{2}$ One set of children, the 1983 birth cohort, was first assessed in Grade 2 because the children were in that grade when the study started.

${ }^{3}$ Two schools also were dropped and replaced by alternative schools before the intervention started because of changes in teacher staffing and support. However, these changes were made before schools had been notified of assignment to condition and cannot threaten the validity of our original experimental design because condition could not have influenced dropout. 
(or 77\%) completed at least 1 year of intervention and a second assessment, and 1,518 (or $70 \%$ ) had at least 2 years of intervention and were assessed at pretest and posttest. The attrition did not appreciably change the distribution of aggression of the sample (see Figure 2). Attrition, defined as unavailability for posttest assessment if pretest assessment was completed, indicated no difference on achievement scores by attrition status, $t(1$, $363)=0.41, n s$, for early treatment sample; $t(1,661)=0.12, n s$, for late treatment. Those who left the study scored higher at pretest on aggression than those who remained: early treatment group $M=1.99, M=1.90, t(1$, $363)=2.04, p<.05$; late treatment group $M=2.35, M=2.18$, $t(660)=2.33, p<.03$. Despite this difference, the entire ranges of achievement and aggression levels are present both in the pre- and postattrition samples (as shown in Figure 2). Also, the attrition rate did not differ significantly between any treatment and the control condition. To replace any missing scores for participants who remained in the study, we imputed replacement values for any missing data for those who have at least one datum at that time (Little \& Rubin, 1987; Little \& Yau, 1998). ${ }^{4}$

On the basis of these participation and attrition rates, our analysis of achievement scores was conducted on subsets of the 1,677 participants who were present for pretest, completed at least 1 year of intervention, and had a second achievement assessment available. However, because peernominated aggression scores were only obtained after the full 2 years of
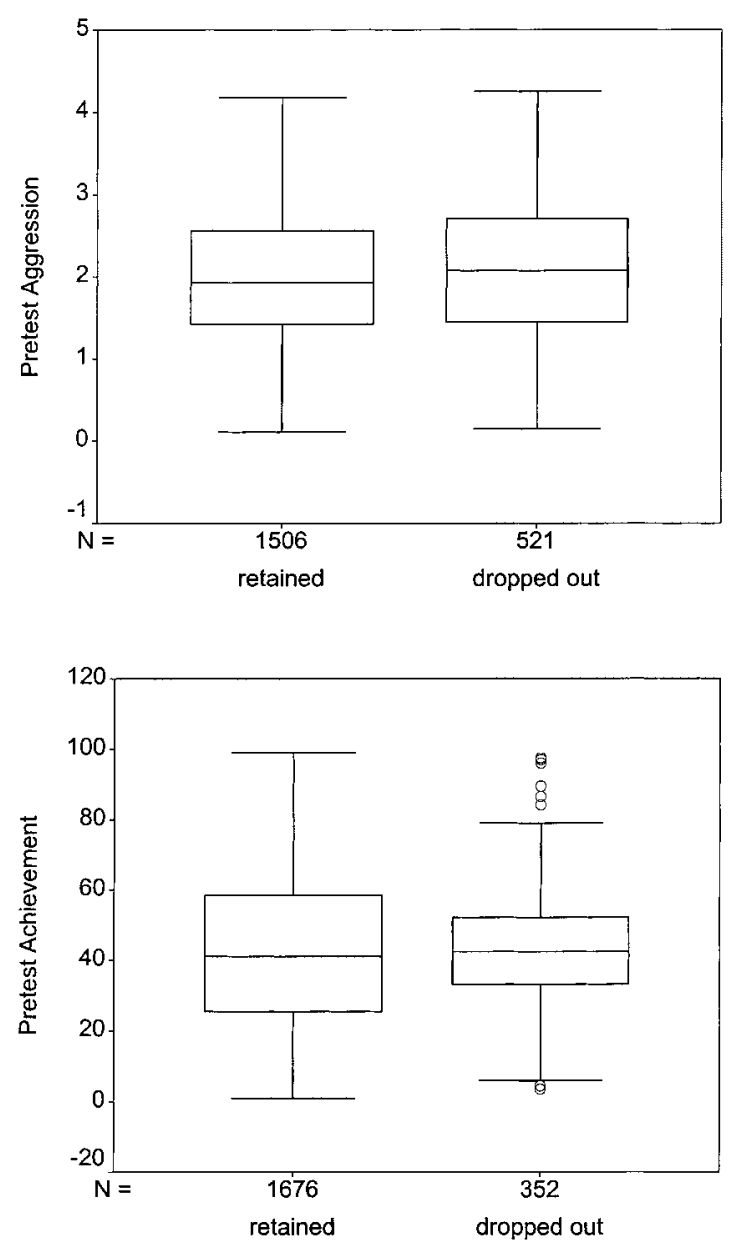

Figure 2. Box plots comparing the distribution of initial aggression and achievement scores of children who contributed data to the analyses with those who dropped out. The upper panel compares aggression scores, and the lower panel compares achievement scores. intervention (early or late), aggressive behavior was analyzed using subsets of the 1,518 participants who were present for pre- and posttest assessments and 2 years of the intervention. Thus, there were slight differences in the sample sizes available for analysis of achievement and aggression outcomes. Within each of these samples, almost one third received only the late intervention (558 and 484 for achievement and achievement analyses, respectively). The other two thirds received the early intervention $(1,118$ and 1,022, respectively). More than one fourth of those who received the early intervention also received the late intervention (291 and 289, respectively). ${ }^{5}$

\section{Assessment Measures}

Aggression was assessed from two sources: peers and teachers. Classmates' nominations were used to assess aggression through the Peer Nomination Inventory (Eron et al., 1971). Children were asked to nominate their classmates who engage in certain behaviors. This instrument is designed for school-age children and assesses, among other things, aggression. The scale's and instrument's relevance, reliability, and validity in field and experimental settings have been demonstrated in numerous studies (Eron, Laulicht, Walder, Farber, \& Spiegel, 1961; Eron et al., 1971; Guerra et al., 1995; Huesmann \& Eron, 1986; Huesmann et al., 1984; Lefkowitz, Eron, Walder, \& Huesmann, 1977). Internal consistency of the Aggression scale is high ( $\alpha=.95$ to .97 in different studies). The scale provides ratios indicating the number of times a child was nominated for each of 10 physically and verbally aggressive behaviors (e.g., pushing and shoving other children, taking other children's belongings without asking, or yelling at other children) compared with the number of times the child could have maximally been nominated by peers. For those classrooms for which peer nominations could not be collected (23.2\% of all assessments), we asked teachers to predict what proportion of a child's peers would nominate the child for each of the questions of the Peer Nomination Inventory. Teachers' predictions of peer nominations of aggression have been shown to be highly reliable $(\alpha=.97)$ and valid estimates of actual peer nominations (Huesmann, Eron, Guerra, \& Crawshaw, 1994). We also used the TRF of the CBCL (Achenbach, 1978, 1991). The scale and measure are well validated and reliable. Coefficient alpha for the TRF Aggression scale is .96. We combined these two scales to form a composite aggression score. Because of the sensitivity of Peer Nominated Aggression to variation among moderately aggressive children, and the sensitivity of the TRF to variation among highly aggressive children, the composite's reliability and validity were higher than either component alone (Spindler \& Huesmann, 1999). ${ }^{6}$ Composite scores can range from 0 to 4.5. The 50th percentile in a national sample of boys was about 1.0. This composite score is used in all aggression analyses in this article.

Academic achievement was assessed using nationally normed percentile rank reading and mathematics scores on the Iowa Test of Basic Skills (ITBS; Hieronymous, Hoover, \& Linquist, 1986) or the California

\footnotetext{
${ }^{4}$ Of the high-risk sample, $34 \%$ had some missing data, although few had substantial data missing. With this state-of-the-art technique, for each missing value, five values are imputed. The replacement value is the mean of the imputed values. In addition, the standard error of any statistic based on the imputed values can be correctly estimated by making use of the variation in the five imputed values. In all analyses in this article, we use the corrected standard errors for significance tests. The version of the hierarchical linear modeling program that we use (Raudenbush \& Congdon, 1999) does this automatically.

${ }^{5}$ The early and late sample sizes do not quite add to the total sample size because a few children had enough data to be included in the early-pluslate sample but not to be in the early sample.

${ }^{6}$ It is computed by the formula: Aggression composite = $1.2 *\left(\log _{10}[\mathrm{CBC}+1]\right)+8.5 *\left(\log _{10}[\mathrm{PRAGG}+1]\right)$.
} 
Achievement Test (CAT; CTB/McGraw-Hill, 1985), which were administered to students as a part of their schools' testing programs. Thus, scores represent the child's achievement level as a nationally referenced rank. Over time, no change in score would mean achievement rates at the national average. Children who spoke insufficient English for testing were assessed with La Prueba de Realización [The Path to Success] (Riverside Publishing Co., 1993) at the discretion of the schools; this test was administered to students as a part of their schools' testing programs. Approximately $80 \%$ of the published reliability coefficients for the CAT are at .8 or above (Salvia \& Yesseldyke, 1991). On the ITBS, reliabilities range from .67 to .95 , and on La Prueba, internal consistency reliabilities range from .77 to .87 in first- through sixth-grade samples.

\section{Assessment Procedures}

Pretests were generally conducted in the spring of the year preceding the 1st year of intervention. Peer nominations, teacher CBCLs, and achievement score data were obtained at pre- and posttest. Teacher data were collected between the 1st and 2nd year of intervention (midtest).

Peer-nomination measures completed by students were administered individually for children in Grade 1. Children in Grade 2 and above were assessed in groups in their regular school classrooms. In classrooms with Spanish-speaking children, bilingual measures were used, and children were permitted to choose the language of testing. Teacher ratings were completed within a 2-week period near the end of the spring semester. Research assistants recorded student achievement test scores annually.

\section{Intervention Procedures, Content, and Fidelity}

Our overall strategy for ensuring fidelity of each intervention component was to provide detailed training manuals and workbooks, intensive group and individual supervision of trainers, progress review, random videotaping and monitoring, and self-reports of topics covered. Our intent was to conduct rigorous process evaluations and monitoring so that any deviations from training as planned could be immediately corrected.

The Level A intervention (classroom general enhancement only) represented the least intrusive program. In this program, teachers received services from trained teacher collaborators. Teacher collaborators had several years of classroom teaching experience and participated in extensive training on classroom collaboration, including weekly meetings with the supervising project investigator. All teachers in a school received 2 years of biweekly seminars focused on classroom management, understanding cultural diversity, encouraging prosocial behavior, and managing conflict. Among teachers, 94\% demonstrated mastery of content at or above the $80 \%$ level. Teachers were observed at least four times during the course of each academic year. Structured feedback was also provided (Cole, VanAcker, Grant, \& Henry, 1993).

Participating teachers from the target grades were also trained to provide the Yes I Can curriculum. One teacher collaborator was assigned exclusively to monitor fidelity and implementation of the curriculum. The overall focus was on teaching children to understand their own and others' feelings, to generate prosocial solutions and effective "action plans," and to reduce endorsement of aggression. A detailed description of the classroom training is available in Guerra and Moore (1991).

The Level B intervention small groups met during the regular school day, once a week for 28 weeks over 2 years (12 weeks in the 1st year and 16 weeks in the 2nd year). Graduate students with advanced training led these groups, assisted by undergraduate coleaders. At least one leader or coleader was from the same ethnic background as the majority of students in their group. Both leaders and coleaders received two initial 6-hr training sessions followed by weekly group and individual supervision by an advanced clinical graduate student (peer training coordinator) during the entire intervention period. Random videotaping and observation of group leaders by the peer training coordinator was conducted. If any problems were noted, supervision frequency was increased and demonstration of skills was required. The peer training coordinator also met weekly with the supervising project investigator. In addition, leaders and coleaders completed a fidelity worksheet at the end of each year's program. On average, 90\% of planned activities were implemented.

The small-group training was designed to change children's aggressionrelated beliefs and behavior and to alter peer group norms toward more prosocial standards of behavior. The training was connected to six areas of peer relations identified by children as most problematic: initiating social interaction, maintaining social interaction, solving interpersonal conflicts, understanding ambiguity, dealing with victimization, and developing friendships (Asher, Rose, Guerra, \& Tolan, 1993). A complete description of the small-group peer-skills training content and procedures is available in Eargle, Guerra, and Tolan (1994).

The Level C family intervention (22 weeks) was delivered by trained clinicians during the 2 nd year of intervention (i.e., when children were in Grades 3 and 6). Procedures for ensuring fidelity in the family component were the same as those used in the small-group training. According to family reports, in $88 \%$ of sessions the planned activities were completed. Process studies indicate the family intervention affected parenting skills and family relationships as expected (Hanish \& Tolan, in press; Tolan, Hanish, McKay, \& Dickey, in press). Of eligible families, $81 \%$ participated to some extent. Almost all (78\%) who started participation completed $75 \%$ or more of the sessions. Mean number of sessions attended was 18.1, with the modal number of sessions attended 22. Participants included all interested family members of the target child, with at least one primary caregiver's attendance required. In most cases, the primary caregiver was the biological mother (74\%), with fathers, grandmothers, and aunts composing the rest.

The family intervention was designed to enhance family skills and communication and to build support networks among participating families. Four modes of intervention were used with all families: (a) multiple family groups were used to introduce each program unit, (b) meetings for each family alone were scheduled to tailor the specific units to individual family needs, (c) weekly telephone calls facilitated continued involvement, and (d) homework assignments were used to reinforce practice of skills learned. A full description of the family intervention is available in Tolan and McKay (1996) and Tolan, Florsheim, McKay, and Kohner (1993).

The control condition schools were each provided funds $(\$ 500 /$ school per year) for purchase of educational materials and periodic in-service presentations. However, we did not provide any intervention services. After completion of the study period, control schools were provided copies of the Yes I Can and teacher training manuals if they requested them.

\section{Results}

We used hierarchical linear modeling to test our hypotheses about aggression and achievement with the appropriate subset of the high-risk children ( $n=1,518$ for aggression and $n=1,677$ for achievement). Assigning schools to conditions was preferred because it considered the context changes we believed were necessary for a successful intervention. Also, this avoided contamination across conditions within schools. Nevertheless, this design posed some challenges for power of analyses. Because participants are nested within schools that are assigned to conditions, we have a nested design in which schools are a "random" effect. We used two-level hierarchical linear models (HLMs) to evaluate pre- and postintervention change. Individuals compose the unit of observation for the first level and schools for the second. This approach not only explicitly models the nesting of participants within schools but also allows the variation attributable to schools to be separated from that attributable to individuals. HLMs also are robust for missing values and make good use of imputed data. We 
used an HLM program that accepts five imputed data sets as input and computes the appropriate tests of specified hypotheses (Bryk, Raudenbush, \& Congdon, 1996; Raudenbush \& Congdon, 1999). (A more detailed technical explanation of HLM approach is available from the authors upon request.)

Given the "stair step," or additive, structure of our experimental design, we selected three planned nonorthogonal comparisons using Dunnett's (1955) "many-one" criterion to determine the key comparisons for each of the above questions. Although there are six possible comparisons that can be done with four groups, only three can be independent (Dunnett, 1955). We chose (a) a comparison of the Level $\mathrm{C}$ full intervention condition with the control condition, (b) a comparison of Level B with the control condition, and (c) a comparison of Level A with the control condition. Accordingly, we conducted other comparisons post hoc to finding significance in any one comparison to illuminate the effect from an independent test.

\section{Aggression Analyses}

In Table 1, we present the observed mean scores on aggression in the intervention and control groups for all three intervention conditions and for all three times of intervention. Using HLM, the first-level model predicted postintervention aggression with an intercept parameter and slope parameters for three personal characteristics: preintervention aggression, gender, and an interaction between gender and preintervention aggression. The second-level model included a constant and three school characteristics: treatment condition, community, and their interaction as predictors of every first-level parameter. A differential effect of the treatment on high- and low-aggressive children would be reflected by treatment condition significantly predicting the coefficient for preintervention aggression in the first-level model. If there were no such effect, then a significant effect of the intervention on overall postintervention aggression would be reflected by treatment condition significantly predicting the intercept in the first-level model. The model also allows us to test for different gender effects and location effects by including parameters for those effects. However, in this sample, ethnicity is confounded with school location and cannot be examined separately. In each analysis reported below, the initial full model was reduced by eliminating the nonsignificant, theoretically uninteresting interactions and redoing the analysis until no further interactions met the criterion for removal. $^{7}$ The main significance tests for treatment effects are summarized in Table 1.

Early intervention period. Our analyses of the early intervention revealed no Pretest $\times$ Condition interactions (i.e., there was homogeneity of regression of posttest on pretest across conditions), so pretest was included only as a simple covariate in all subsequent analyses. Similarly, there were no significant Gender $\times$ Condition interactions, so gender was included only as a covariate in subsequent tests of condition. As Table 1 shows, there were also no Condition $\times$ Community interactions or main effects for condition in the analyses of the effects of the Level A and Level B interventions. However, the analysis of Level C intervention showed a significant Community $\times$ Treatment interaction on mean postintervention aggression, $t(9)=4.02, p<.004$. A further examination of HLM contrasts within communities revealed that this intervention condition significantly decreased aggression at posttest for treated youths in communities with greater school and community resources (Aurora); a 0.59 standard deviation greater than the change for control youths, $t(9)=2.66, p<.03$. However, in inner-city schools (Chicago), the Level $\mathrm{C}$ treatment increased aggression by 0.42 standard deviation compared with the control group, $t(9)=2.98, p<.02$. These are substantial effect sizes by the standards of prevention research. Figure 3 illustrates these effects of the Level $\mathrm{C}$ treatment on the aggression means for schools in the two communities.

In the early intervention sample, boys increased significantly more in aggression than girls (effect size $=0.27 S D, p<.01$ ). However, there were no differential treatment effects for boys and girls. In addition, as expected, pretest was significantly related to posttest $(p<.001)$. School had an effect on posttest means independent of condition and community in each analysis and generally also had a significant effect on pre- and posttest slope.

Late intervention period. For the late intervention, there were no Pretest $\times$ Condition interactions or Gender $\times$ Condition interactions, and both variables were included in the final models as simple covariates. As Table 2 shows, there was no detectable effect of Level A or Level $\mathrm{C}$ on aggression either as a function of community or as a main effect. However, Level B participants were relatively more aggressive at posttest than were controls $t(9)=2.69, p=.025$, effect size $=0.62 S D)$.

Pretest was significantly related to posttest, and school had a significant effect on posttest aggression. There were no differential effects of the late intervention on male and female participants, and, unlike Grades 1-3, male participants did not register greater increases in aggression than female participants.

Early-plus-late intervention. The effects of receiving both the early and late intervention were evaluated with a three-level HLM model, in which time was the first level, person was the second level, and school was the third level. For these analyses, there were three time points at which aggression was measured: pre-early intervention, post-early/pre-late intervention, and postlate intervention.

As Table 1 shows, for participants who received both the early and late intervention, the Level $\mathrm{C}$ Condition $\times$ Community interaction that had been found for the early intervention was replicated, $t(261)=4.47, p<.001$. An analysis of the HLM effects within each community revealed that participants in Aurora who received the Level $\mathrm{C}$ intervention benefited from the intervention, whereas those in Chicago did not. The effects are shown in Figure 3. Children in Aurora who received the Level C intervention decreased in aggression from the 1st-grade pretest to the 6th-grade posttest, whereas the control children in Aurora increased, $t(261)=2.15, p<.04$, effect size $=0.65 S D$. However, in Chicago, children who received the Level $\mathrm{C}$ treatment increased in aggression from 1st-grade pretest to 6th-grade posttest, whereas control school children decreased in aggression, $t(224)=4.55$, $p<.001$, effect size $=1.07$ SD. Neither the Level A nor Level B intervention showed a significant effect on aggression from Grades 1-6 in either Aurora or Chicago.

In all of the analyses, gender was a significant predictor of posttest aggression $(p<.001$; effect sizes $=0.49-0.56 S D)$ and

\footnotetext{
${ }^{7}$ A detailed Appendix describing the statistical models is available on request.
} 
Table 1

Observed Mean Aggression Scores (and Standard Deviations) and HLM Tests of Effects for Three Intervention Periods

\begin{tabular}{|c|c|c|c|c|c|c|c|c|c|c|c|c|c|c|c|}
\hline \multirow[b]{2}{*}{ Sample } & \multicolumn{5}{|c|}{ Level A } & \multicolumn{5}{|c|}{ Level B } & \multicolumn{5}{|c|}{ Level C } \\
\hline & Control & Intervention & $d f$ & $\mathrm{HLM} t$ & $p$ & Control & Intervention & $d f$ & $\mathrm{HLM} t$ & $p$ & Control & Intervention & $d f$ & $\mathrm{HLM} t$ & $p$ \\
\hline \multicolumn{16}{|c|}{ Early intervention } \\
\hline \multicolumn{16}{|l|}{ Total } \\
\hline Pre & $1.78(0.91)$ & $2.02(.96)$ & & & & $1.73(0.91)$ & $1.84(0.94)$ & & & & $1.76(0.91)$ & $1.97(0.93)$ & & & \\
\hline Post & $1.76(0.99)$ & $2.06(1.02)$ & & & & $1.73(1.00)$ & $1.76(1.02)$ & & & & $1.74(0.99)$ & $1.90(1.05)$ & & & \\
\hline Post minus pre & -0.02 & 0.04 & & & & 0.00 & -0.08 & & & & -0.02 & -0.07 & & & \\
\hline$N$ & 254 & 261 & & & & 211 & 287 & & & & 240 & 220 & & & \\
\hline \multicolumn{16}{|l|}{ Chicago } \\
\hline Pre & $1.88(0.73)$ & $2.20(0.76)$ & & & & $1.74(0.75)$ & $2.02(0.67)$ & & & & $1.81(0.74)$ & $1.91(0.70)$ & & & \\
\hline Post & $1.73(0.83)$ & $1.95(0.96)$ & & & & $1.62(0.82)$ & $2.04(0.87)$ & & & & $1.67(0.83)$ & $2.12(0.89)$ & & & \\
\hline Post minus pre & -0.15 & -0.25 & & & & -0.12 & 0.02 & & & & -0.14 & 0.21 & & & \\
\hline$n$ & 132 & 120 & & & & 89 & 82 & & & & 118 & 120 & & & \\
\hline \multicolumn{16}{|l|}{ Aurora } \\
\hline Pre & $1.72(0.71)$ & $1.86(0.72)$ & & & & $1.72(0.71)$ & $2.02(0.67)$ & & & & $1.72(0.71)$ & $2.03(0.74)$ & & & \\
\hline Post & $1.81(1.03)$ & $2.15(0.88)$ & & & & $1.81(1.03)$ & $2.04(0.87)$ & & & & $1.81(1.03)$ & $1.63(1.10)$ & & & \\
\hline Post minus pre & -0.02 & 0.19 & & & & 0.00 & 0.02 & & & & 0.09 & -0.40 & & & \\
\hline$n$ & 122 & 141 & & & & 122 & 205 & & & & 122 & 100 & & & \\
\hline \multicolumn{16}{|l|}{ Effect } \\
\hline Condition $\times$ Community (pre as cov.) & & & 9 & 1.12 & $n s$ & & & 6 & -0.99 & $n s$ & \multirow{2}{*}{\multicolumn{2}{|c|}{ Tested within community }} & 9 & -4.02 & $<.003$ \\
\hline Condition (pre as cov.) & & & 11 & 0.75 & $n s$ & & & 8 & -0.04 & $n s$ & & & & & \\
\hline \multicolumn{16}{|c|}{ Late intervention } \\
\hline \multicolumn{16}{|l|}{ Total } \\
\hline Pre & $2.29(0.81)$ & $2.33(0.82)$ & & & & $2.34(0.81)$ & $2.04(0.93)$ & & & & $2.29(0.81)$ & $2.10(0.89)$ & & & \\
\hline Post & $1.86(0.93)$ & $2.27(1.01)$ & & & & $1.78(1.80)$ & $2.03(1.09)$ & & & & $1.86(0.93)$ & $1.84(1.00)$ & & & \\
\hline Post minus pre & -0.43 & -0.06 & & & & -0.56 & -0.01 & & & & -0.43 & -0.26 & & & \\
\hline$N$ & 98 & 122 & & & & 77 & 145 & & & & 98 & 119 & & & \\
\hline \multicolumn{16}{|l|}{ Chicago } \\
\hline Pre & $2.23(0.75)$ & $2.22(0.74)$ & & & & $2.32(0.70)$ & $2.48(0.75)$ & & & & $2.23(0.75)$ & $2.23(0.70)$ & & & \\
\hline Post & $1.88(0.89)$ & $2.19(0.86)$ & & & & $1.68(0.90)$ & $2.31(0.96)$ & & & & $1.88(0.89)$ & $2.11(0.78)$ & & & \\
\hline Post minus pre & -0.35 & -0.03 & & & & -0.64 & -0.17 & & & & -0.35 & -0.12 & & & \\
\hline$n$ & 51 & 52 & & & & 30 & 37 & & & & 51 & 49 & & & \\
\hline \multicolumn{16}{|l|}{ Aurora } \\
\hline Pre & $2.36(0.82)$ & $2.41(0.80)$ & & & & $2.36(0.82)$ & $1.88(0.92)$ & & & & $2.36(0.82)$ & $2.00(0.70)$ & & & \\
\hline Post & $1.85(0.99)$ & $2.34(1.09)$ & & & & $1.85(0.99)$ & $1.94(1.10)$ & & & & $1.85(0.99)$ & $1.65(1.08)$ & & & \\
\hline Post minus pre & -0.51 & -0.07 & & & & -0.51 & 0.06 & & & & -0.51 & -0.35 & & & \\
\hline$n$ & 47 & 70 & & & & 47 & 108 & & & & 47 & 70 & & & \\
\hline \multicolumn{16}{|l|}{ Effect } \\
\hline Condition $\times$ Community (pre as cov.) & & & 7 & 0.54 & $n s$ & & & 6 & -0.24 & $n s$ & & & 7 & -0.36 & $n s$ \\
\hline Condition (pre as cov.) & & & 10 & 2.13 & $<.06$ & & & 9 & 2.69 & $<.03$ & & & 10 & 0.76 & $n s$ \\
\hline
\end{tabular}

Early + late intervention

$\begin{array}{lcc}\text { Total } & & \\ \text { Pre } & 1.79(0.70) & 1.97(0.90) \\ \text { Post early } & 1.73(0.97) & 2.18(1.01) \\ \text { Post late } & 1.50(1.00) & 1.94(1.08) \\ \text { Post late minus pre } & -0.29 & -0.03 \\ N & 74 & 81 \\ \text { Chicago } & & \\ \quad \text { Pre } & 1.97(0.65) & 2.13(0.89) \\ \text { Post early } & 1.89(0.91) & 2.20(1.00) \\ \text { Post late } & 1.38(0.92) & 2.12(0.97) \\ \text { Post late minus pre } & -0.59 & -0.01 \\ n & 47 & 50 \\ \text { Aurora } & & \\ \quad \text { Pre } & 1.49(0.66) & 1.69(0.87) \\ \text { Post early } & 1.47(1.04) & 2.16(0.96) \\ \text { Post late } & 1.72(1.13) & 1.68(1.16) \\ \text { Post late minus pre } & 0.23 & -0.01 \\ n & 27 & 31 \\ \text { Effect } & & \\ \text { Condition } \times \text { Time } \times \text { Community } & & \\ \text { Condition } \times \text { Time } & & \\ \end{array}$

$8 \quad 1.14 \quad$ ns $\quad 235 \quad 1.64 \quad n s \quad$ Tested within community

Note. All effects are tested with a two-level or three-level (for early-plus-late) hierarchical linear model (HLM) that includes gender as a Level 1 variable. However, gender had no significant interactions with condition and was retained only as a covariate (cov.) in the final models shown. Effects are tested hierarchically, so interactions of condition with community are tested before main effects. Where this interaction was significant, tests of effects within each community replace tests of main effects of condition. Where this interaction was nonsignificant, the main effect of condition is tested with community as covariate (see Footnote 7).

${ }^{a}$ Degrees of freedom are greater because significance tests showed parameter did not vary randomly between schools and could be treated as fixed effect. 

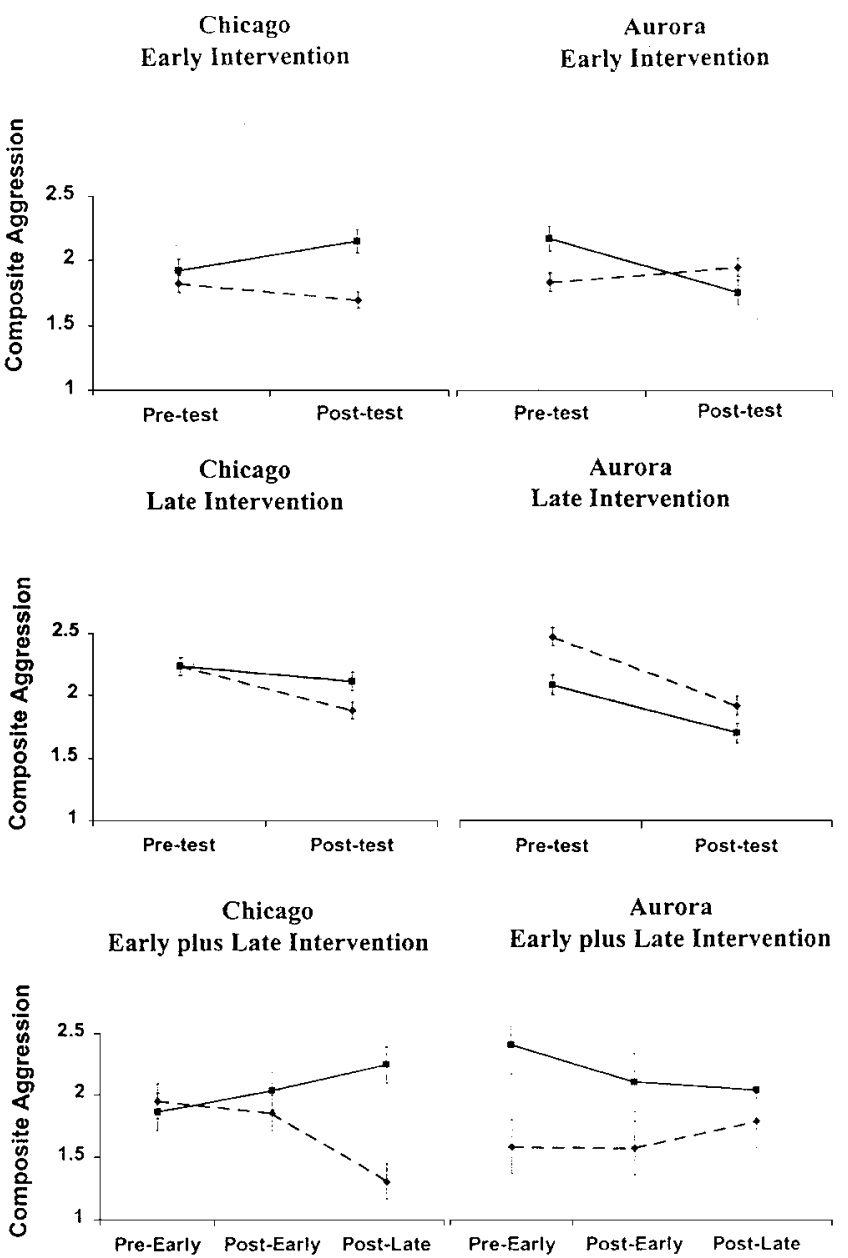

Figure 3. Changes in mean aggression scores for the early, late, and early-plus-late administration of the Level C (classroom plus small-group plus family) intervention plotted separately for Chicago and Aurora. Solid lines $=$ Level C; broken lines $=$ control group.

was included as a covariate in the HLM models, but the effects of the intervention did not differ for boys and girls. Again, school accounted for a significant portion of variance in aggression, as did individual variance. In other words, on average, the more aggressive children were before the early intervention, the more aggressive they were after the late intervention.

In summary, our results show that in schools serving poor urban communities with more resources, the Level C (full) intervention seems to reduce aggressive behavior of high-risk children when delivered in the early grades or when delivered early and continued later. However, in schools and communities with few resources, this same intervention seems to inhibit a naturally occurring decrease in aggression. In both communities, the less comprehensive Level A and B interventions do not seem to affect aggression among this group when delivered early. None of the interventions seem to reduce aggression among high-risk children when only delivered in the late elementary grades. In fact, when delivered in the late elementary grades, the Level B intervention seems to have a negative effect on aggression; it may be blocking normal declines in aggression.
Additional analyses regarding aggression effects. To help clarify the meaning of these results, we conducted several supplementary analyses. First, following Dunnett's (1955) approach, we compared the Level A, B, and C interventions with each other, separately in Chicago and Aurora. We found that children who received the Level C intervention in Aurora had improved not only more than control children but also significantly more than Level A children, $t(9)=4.53, p<.002$, and marginally more than Level B children, $t(6)=1.90, p<.10$. In Chicago, Level C children's relative aggression level was not only higher than control children but also higher than Level A and Level B children, although not significantly higher, $t(9)=1.52, n s$, and $t(6)=-0.49, n s$, respectively. These results suggest that it is the family component of the intervention, rather than the classroom or small-group component, that is particularly relevant in decreasing or increasing aggression.

Second, we repeated the HLM analyses with average family income for each school used as a covariate at the school level and with individual free-lunch status as a covariate at the individual level. None of the results changed. This suggests that the difference in effectiveness of the Level $\mathrm{C}$ intervention between Chicago and Aurora is not simply due to greater poverty in Chicago. Third, we reanalyzed the HLM models after eliminating children who received what we considered a small dose on any intervention component (less than one third completion of any program). The results followed the same pattern as those from the full high-risk sample, but the effect sizes and significance levels were reduced. This shows that even children who received a relatively small dose of the full intervention were affected. ${ }^{8}$

We also evaluated the impact of the early intervention in terms of clinical significance (Kendall, Marrs-Garcia, Nath, \& Sheldrick, 1999). We calculated $T$ scores for TRF Externalizing scale scores using the standardization scales published by Achenbach (1991). We used the full Externalizing scale scores because the clinical cutoffs are more reliable than the Aggression scale scores alone. The Externalizing scale includes more items, although much of it is composed of items from the Aggression scale. We used Achenbach's suggested clinical cut score of $T \geq 67$ to equate to a clinical range score. On the basis of this cut score, we categorized participants into three groups based on the relation between pre- and post-TRF Externalizing scores: $0=$ no change in clinical status, $1=$ changed from clinically nonsignificant to significant, and $-1=$ changed from clinically significant to nonsignificant score. We cross-tabulated this variable against intervention condition within location, using only the schools and waves of data used in the main analysis, to replicate the significant effects in the main analyses. There was a significant difference between Level $\mathrm{C}$ treatment and control in the Aurora schools, $\chi^{2}(2, N=$ $315)=21.65, p<.001$, and a marginal effect in the Chicago schools, $\chi^{2}(2, N=264)=5.27, p<.10$. In Aurora, the difference

\footnotetext{
${ }^{8}$ A complete analysis of dosage effects requires introducing dose as a person-level variable in our HLM model, computing a propensity score, and reanalyzing each HLM model. Such an approach is technically complex, quasi-experimental (because dose received depends on other individual characteristics), and beyond the scope of an initial-outcomes article. We plan to address the issue in a separate article. In any case, the true-experimental, intent-to-treat HLM approach adopted here is a more conservative approach to testing for treatment effects.
} 
Table 2

Observed Mean Achievment Percentile Test Scores (and Standard Deviations) and HLM Tests of Effects for Three Intervention Periods

\begin{tabular}{|c|c|c|c|c|c|c|c|c|c|c|c|c|c|c|c|}
\hline \multirow[b]{2}{*}{ Sample } & \multicolumn{5}{|c|}{ Level A } & \multicolumn{5}{|c|}{ Level B } & \multicolumn{5}{|c|}{ Level C } \\
\hline & Control & Intervention & $d f$ & $\mathrm{HLM} t$ & $p$ & Control & Intervention & $d f$ & $\mathrm{HLM} t$ & $p$ & Control & Intervention & $d f$ & $\mathrm{HLM} t$ & $p$ \\
\hline & & & & & & rly intervention & & & & & & & & & \\
\hline Total & & & & & & & & & & & & & & & \\
\hline Pre & $51.84(22.8)$ & $40.48(21.2)$ & & & & $53.58(23.7)$ & $50.21(25.0)$ & & & & $51.67(23.3)$ & $41.65(19.1)$ & & & \\
\hline Mid & $45.61(24.2)$ & $39.20(23.3)$ & & & & 46.99 (24.8) & $44.11(27.7)$ & & & & $46.03(24.7)$ & $41.26(22.5)$ & & & \\
\hline Post & $42.29(22.0)$ & $45.99(20.1)$ & & & & 43.76 (20.9) & $45.00(23.9)$ & & & & $43.08(22.1)$ & 43.18 (19.6) & & & \\
\hline Post minus pre & -9.55 & 5.51 & & & & $-9.82(26.8)$ & $-5.21(21.6)$ & & & & $-8.59(28.0)$ & $1.53(22.0)$ & & & \\
\hline$N$ & 277 & 280 & & & & 229 & 314 & & & & 264 & 245 & & & \\
\hline Chicago & & & & & & & & & & & & & & & \\
\hline Pre & $48.98(25.0)$ & $37.90(23.4)$ & & & & $51.62(27.1)$ & $35.76(21.8)$ & & & & 48.33 (25.9) & 35.95 (21.4) & & & \\
\hline Mid & $40.46(22.1)$ & $35.06(22.5)$ & & & & $41.10(23.0)$ & 30.31 (18.9) & & & & $40.76(23.0)$ & 45.97 (20.9) & & & \\
\hline Post & $35.76(22.5)$ & 39.75 (18.5) & & & & $35.90(20.8)$ & $28.59(18.8)$ & & & & $36.62(23.1)$ & 37.69 (19.4) & & & \\
\hline Post minus pre & -13.22 & 1.85 & & & & -15.72 & -7.17 & & & & -11.71 & 1.74 & & & \\
\hline$n$ & 147 & 129 & & & & 98 & 85 & & & & 133 & 131 & & & \\
\hline Aurora & & & & & & & & & & & & & & & \\
\hline Pre & 55.14 (22.6) & $42.81(21.5)$ & & & & 55.14 (22.6) & $55.57(25.5)$ & & & & 55.14 (22.6) & $48.14(16.2)$ & & & \\
\hline Mid & $51.42(25.3)$ & $42.73(23.6)$ & & & & $51.42(25.3)$ & $49.23(28.7)$ & & & & $51.42(25.3)$ & $47.46(22.5)$ & & & \\
\hline Post & $49.76(18.9)$ & $51.45(20.0)$ & & & & 49.76 (18.9) & $51.51(22.5)$ & & & & 49.76 (18.9) & 49.94 (17.9) & & & \\
\hline Post minus pre & -1.38 & 8.64 & & & & -5.38 & -4.06 & & & & -5.38 & 1.80 & & & \\
\hline$n$ & 130 & 151 & & & & 130 & 229 & & & & 130 & 112 & & & \\
\hline Effect & & & & & & & & & & & & & & & \\
\hline Condition $\times$ Time $\times$ Community & & & 9 & 0.49 & ns & & & 6 & 1.06 & $n s$ & & & 9 & 0.65 & $n s$ \\
\hline Condition $\times$ Time & & & 12 & 2.70 & $<.02$ & & & 9 & 0.54 & ns & & & 12 & 1.25 & $n s$ \\
\hline & & & & & & ate intervention & & & & & & & & & \\
\hline Total & & & & & & & & & & & & & & & \\
\hline Pre & 34.95 (18.6) & $34.37(21.5)$ & & & & $36.42(19.1)$ & $39.30(13.4)$ & & & & 34.95 (18.6) & $36.66(18.2)$ & & & \\
\hline Mid & $37.02(21.2)$ & $34.91(21.7)$ & & & & $38.68(21.4)$ & $40.48(21.3)$ & & & & $37.02(21.2)$ & 38.35 (18.7) & & & \\
\hline Post & $43.17(19.3)$ & $41.64(21.8)$ & & & & 44.45 (18.4) & $46.83(19.5)$ & & & & 43.17 (19.3) & $49.08(20.6)$ & & & \\
\hline Post minus pre & $8.22(19.4)$ & $7.27(21.5)$ & & & & $8.03(18.7)$ & $7.53(20.7)$ & & & & $8.22(19.4)$ & 12.42 & & & \\
\hline$n$ & 113 & 153 & & & & 89 & 154 & & & & 113 & 136 & & & \\
\hline Chicago & & & & & & & & & & & & & & & \\
\hline Pre & $34.01(23.1)$ & $23.94(17.7)$ & & & & $29.43(23.6)$ & $33.49(20.3)$ & & & & $34.01(23.1)$ & $29.46(18.2)$ & & & \\
\hline Mid & $37.53(21.2)$ & $26.45(18.4)$ & & & & $36.25(25.5)$ & $32.22(19.7)$ & & & & $37.53(21.2)$ & $30.27(18.7)$ & & & \\
\hline Post & $40.62(19.3)$ & $32.42(20.2)$ & & & & $38.72(21.6)$ & $40.09(15.9)$ & & & & $40.62(19.3)$ & $38.65(20.6)$ & & & \\
\hline Post minus pre & 8.22 & 8.48 & & & & 17.12 & 6.60 & & & & 8.22 & 9.19 & & & \\
\hline$n$ & 58 & 61 & & & & 35 & 43 & & & & 58 & 58 & & & \\
\hline Aurora & & & & & & & & & & & & & & & \\
\hline Pre & $40.62(17.1)$ & $41.84(23.2)$ & & & & $40.62(17.1)$ & $42.00(18.2)$ & & & & $40.62(17.1)$ & $41.85(16.1)$ & & & \\
\hline Mid & $40.26(18.4)$ & $40.65(22.0)$ & & & & $40.26(18.4)$ & $43.68(21.1)$ & & & & $40.26(18.4)$ & $44.44(15.7)$ & & & \\
\hline Post & 48.47 (14.7) & $49.52(20.1)$ & & & & 48.47 (14.7) & $49.72(20.2)$ & & & & $48.47(14.7)$ & $57.00(16.4)$ & & & \\
\hline Post minus pre & 7.85 & 7.68 & & & & 7.85 & 7.72 & & & & 7.85 & 15.15 & & & \\
\hline$n$ & 54 & 90 & & & & 89 & 111 & & & & 54 & 77 & & & \\
\hline Effect & & & & & & & & & & & & & & & \\
\hline Condition $\times$ Time $\times$ Community & & & 7 & 0.09 & ns & & & 6 & 0.05 & $n s$ & & & 7 & 0.29 & $n s$ \\
\hline Condition $\times$ Time & & & 11 & 0.15 & $n s$ & & & 9 & 0.24 & $n s$ & & & 11 & 0.27 & $n s$ \\
\hline & & & & & Early & + late intervent & & & & & & & & & \\
\hline Total & & & & & & & & & & & & & & & \\
\hline Pre early & $45.57(25.0)$ & $35.54(21.1)$ & & & & $47.30(26.6)$ & $41.87(24.2)$ & & & & $46.72(25.9)$ & $42.14(21.0)$ & & & \\
\hline Mid early & $41.16(24.7)$ & $35.96(21.7)$ & & & & $43.06(25.0)$ & $36.66(21.9)$ & & & & $41.82(24.8)$ & $37.50(22.9)$ & & & \\
\hline Post early & $41.17(25.1)$ & $41.88(21.5)$ & & & & $46.57(24.0)$ & $39.62(23.0)$ & & & & 45.54 (23.7) & $38.58(19.2)$ & & & \\
\hline Mid late & $38.45(23.2)$ & $37.83(20.4)$ & & & & $38.39(21.1)$ & $42.71(24.6)$ & & & & $38.30(21.7)$ & $36.98(16.6)$ & & & \\
\hline Post late & $47.44(20.5)$ & $42.50(20.6)$ & & & & 45.64 (16.7) & $42.92(20.3)$ & & & & $47.39(20.9)$ & $47.12(20.2)$ & & & \\
\hline Post late minus pre early & $1.87(25.9)$ & $6.96(20.4)$ & & & & $-1.66(25.3)$ & $1.05(23.6)$ & & & & $0.67(26.6)$ & $4.98(23.7)$ & & & \\
\hline 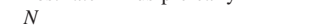 & 74 & 81 & & & & 57 & 70 & & & & 64 & 66 & & & \\
\hline Chicago & & & & & & & & & & & & & & & \\
\hline Pre early & $35.57(19.0)$ & $36.65(22.5)$ & & & & $33.20(19.5)$ & 35.37 (21.3) & & & & $34.86(19.5)$ & $38.11(22.6)$ & & & \\
\hline Mid early & $34.38(21.7)$ & $37.71(22.7)$ & & & & $34.07(21.0)$ & $32.96(18.2)$ & & & & $33.65(21.0)$ & $31.28(19.3)$ & & & \\
\hline Post early & $30.78(24.1)$ & $38.50(21.8)$ & & & & $35.14(25.5)$ & $27.36(20.9)$ & & & & $35.56(24.4)$ & $31.32(18.6)$ & & & \\
\hline Mid late & $33.60(23.3)$ & $41.30(20.8)$ & & & & $30.75(18.7)$ & $30.95(19.3)$ & & & & $32.04(20.4)$ & $32.92(14.5)$ & & & \\
\hline Post late & $44.79(23.8)$ & $42.48(24.7)$ & & & & $40.00(19.0)$ & $29.02(16.0)$ & & & & $43.97(25.2)$ & $40.51(19.7)$ & & & \\
\hline Post late minus pre early & 9.22 & 5.83 & & & & 6.80 & -6.35 & & & & $0.67(26.6)$ & $4.98(23.7)$ & & & \\
\hline$n$ & 47 & 50 & & & & 30 & 33 & & & & 37 & 40 & & & \\
\hline Aurora & & & & & & & & & & & & & & & \\
\hline Pre early & $62.97(24.9)$ & $33.73(18.9)$ & & & & $62.97(24.9)$ & $47.67(25.4)$ & & & & $62.97(24.9)$ & $48.35(17.0)$ & & & \\
\hline Mid early & $52.72(25.7)$ & $33.05(19.9)$ & & & & $52.72(25.7)$ & 39.95 (24.6) & & & & $52.72(25.7)$ & $47.08(25.1)$ & & & \\
\hline Post early & $58.86(14.8)$ & $47.47(20.3)$ & & & & $58.86(14.8)$ & $50.54(19.1)$ & & & & $58.86(14.8)$ & $49.46(14.7)$ & & & \\
\hline Mid late & 47.57 (20.6) & $32.20(18.7)$ & & & & 47.57 (20.6) & $52.39(24.4)$ & & & & 47.57 (20.6) & $43.76(18.1)$ & & & \\
\hline Post late & $52.74(9.6)$ & $42.53(13.1)$ & & & & $52.74(9.6)$ & $54.72(15.6)$ & & & & $52.74(9.6)$ & $58.13(16.0)$ & & & \\
\hline Post late minus pre early & -10.23 & 8.80 & & & & -10.23 & 7.05 & & & & -10.23 & 9.78 & & & \\
\hline$n$ & 27 & 31 & & & & 27 & 37 & & & & 27 & 26 & & & \\
\hline Effect & & & & & & & & & & & & & & & \\
\hline Condition $\times$ Time $\times$ Community & & & 5 & 1.52 & $n s$ & & & $160^{\mathrm{a}}$ & 1.55 & $n s$ & & & 5 & 1.32 & $n s$ \\
\hline Condition $\times$ Time & & & 8 & 0.60 & ns & & & 5 & 0.51 & $n s$ & & & 8 & 0.37 & $n s$ \\
\hline
\end{tabular}

Note. All effects are tested with a two-level or three-level (for early-plus-late) hierarchical linear model (HLM) that includes gender as a Level 1 variable. However, gender had no significant interactions with condition and was retained only as a covariate in the final models shown. Effects are tested hierarchically, so interactions of condition with community are tested before main effects. Where this interaction was significant, tests of effects within each community replace tests of main effects of condition. Where this interaction was nonsignificant, the main effect of condition is tested with community as covariate. (More details of the analyses are available on request.)

${ }^{a}$ Degrees of freedom are greater because significance tests showed parameter did not vary randomly between schools and could be treated as "fixed" effect. 
is due to a larger proportion of children in Level $\mathrm{C}$ condition moving from clinical to nonclinical status $(18.3 \%$ vs. $3.1 \%$, standardized residual $=4.4$.). The trend found in Chicago is for the same effect $(10.3 \%$ vs. $3.4 \%$, standardized residual $=2.2)$. There was no difference between conditions in the number of children moving from nonclinical status to clinical status in Aurora $(8.5 \%$ vs. $13.0 \%$, standardized residual $=1.3)$ or Chicago $(19.3 \%$ vs. $22.7 \%$, standardized residual $=0.7$ ). These results suggest the "positive" effect of the full intervention in Aurora extended to the most at-risk youths. However, in contrast, the "negative" effect in Chicago for average aggression level did not occur when the most at-risk of the high-risk youths are considered. There was a marginal positive effect of the full intervention. To further understand the variation in effects between the composite aggression measure and the TRF clinical scores, we examined the pretest and posttest distributions of the composite aggression measure by intervention condition and location. This graphical examination suggested that the median levels of aggression increased in both the full intervention and in the control conditions in Chicago. However, the length of the upper tail of the distribution grew more in the control condition. Thus, although there was an increase in median aggression comparison of full treatment to control, there was an opposite trend when clinical level status was compared.

\section{Achievement Analyses}

Because achievement scores were based on standardized tests and could be obtained from school archives, we had data available for most children before, during, and after each intervention period. Because these were nationally standardized achievement tests, the percentile rank scores represented each child's position in comparison with a national normative sample. The mean composite achievement test scores are shown in Table 2 for each assessment period, each intervention condition, at all three times of intervention.

To test for significant effects on children's achievement, we conducted HLM analyses using three time points for evaluating the early and the late intervention each, and five time points for evaluating the effect of receiving an early and a late intervention. Having more data points permits a more reliable estimate of effects. Time was used as the first-level unit, person as the secondlevel unit, and school as the third-level unit. The strategy of eliminating terms from the models was the same as in the aggression analyses. The main significance tests for treatment effects are summarized in Table 2.

Early intervention period. The average growth trajectories for relative achievement level during the early intervention period are plotted in Figure 4. The early Level A intervention significantly improved relative achievement level. The average trajectory from first to third grade was significantly steeper for Level A high-risk children $(B=4.56)$ than for control children $(B=-8.77)$, $t(12)=2.79, p<.02$, effect size $=0.83 S D$. The growth trajectories for Level B and Level C were also more positive than the control trajectories. However, the differences were not significant, which was surprising given that all three levels of intervention included the general enhancement classroom intervention that was theoretically linked to improved relative achievement level. These results suggest that Level A children showed an average increase of 5.5 percentile rank points, whereas controls slipped an additional 9.6 points. This represented a net difference of 16.1 percentile rank points in children's relative percentile rank standings.

Additional analyses on achievement. To understand why the effect was significant only for Level A, we tested to see whether the classroom enhancement intervention was delivered with greater fidelity in the schools in which it was the only component. The intervention dosage data revealed that this was not the case. The number of feedback sessions received by teachers, and the number of Yes I Can sessions completed were no greater in the Level A schools than in the Level B and C schools, $t(1$, $834)=0.84, n s ; F(1,965)=0.23, n s$, respectively. We comment on the likely reasons for this finding in the Discussion section.

Late intervention period and early-plus-late intervention period. The significant effect of the Level A intervention in improving relative achievement level was not replicated among the children who received the intervention only in the fifth and sixth grades or among the children who received the intervention during both periods. Similarly, there was no significant effect of the Level B or $\mathrm{C}$ interventions for either of these samples. However, as one can see from Table 2, the general trend for all who had received the early intervention only or early plus late was for the treated children to improve more on relative achievement level than the control children. Of the six possible comparisons of such groups in

\section{Chicago and Aurora Early Intervention: Level A}

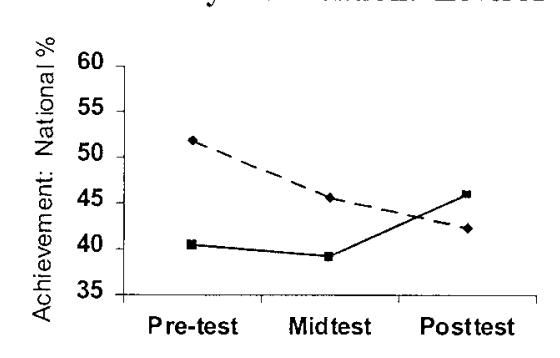

\section{Chicago and Aurora Early Intervention: Level B}

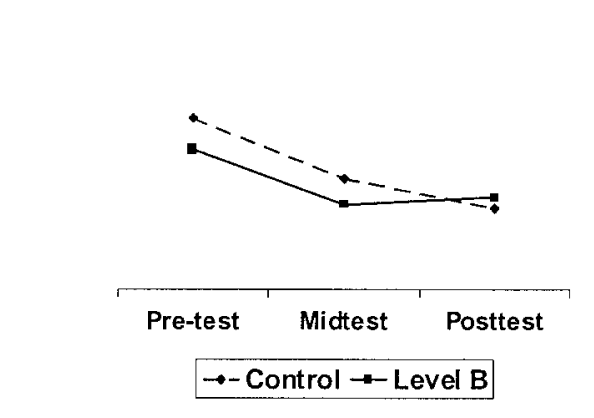

\section{Chicago and Aurora Early Intervention: Level C}

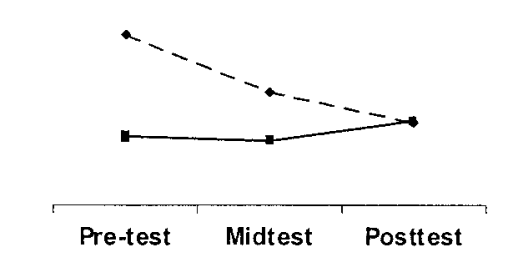

Figure 4. Changes in mean achievement scores for Chicago and Aurora children combined when intervention was administered in the early grades. 
Table 1, the intervention group improved more from initial pretest to final posttest in all six ( $p<.016$ by a sign test).

In each comparison, the children in Aurora scored higher on achievement than the children in Chicago ( $t$ ranging from 4.40 to 6.91 with $p$ always less than .02 , effect size ranging from 0.63 $S D$ to $0.97 S D$ ). In every HLM analysis, school within community also accounted for significant and substantial variance in achievement. There were no significant gender differences in overall academic achievement, though generally boys scored somewhat lower on reading achievement and higher on math achievement. In no case did the intervention affect achievement differently for boys and girls.

\section{Discussion}

The purpose of this study was to evaluate the proximal effects on aggression and academic achievement of three levels of a cognitive-ecological preventive intervention for children living in inner-city and other urban poor communities. In addition, we were interested in the variations in effects due to the timing of intervention, and the school and community resources and constraints. Our hypothesis was that the general enhancement classroom intervention would enhance academic achievement but would not be adequate to prevent or mitigate aggression among high-risk youths. For this behavior, more extensive interventions would be needed, with the greatest benefit accruing from the most extensive intervention (one including peers and families). We also expected effects to be greater for the early intervention and in the urban poor communities and schools (not inner city) and to be similar for boys and girls. The complex set of results partially supports the basic hypothesis and its corollaries.

The results provide support for the effectiveness in preventing aggression of a comprehensive intervention for high-risk youths that focuses on social cognition, behavior management, and norms about aggression and that involves both peer issues and families-if it is delivered early in communities with adequate resources. There were significant effects of the most comprehensive intervention on aggressive behavior when it was delivered to children during the early school years in urban poor communities. When the early intervention was followed by an additional 2-year intervention during Grades 5 and 6, the magnitude of effect doubled. The effects of the early intervention appear to be enhanced with a second exposure of the combined intervention. However, the results are more complicated when the intervention was delivered during the early grades in inner-city schools. The median aggression level decreased for controls but not for the full intervention group. However, this average effect also contained a positive effect for the most aggressive youths (those scoring in the clinical range at pretest).

None of the interventions were effective in preventing aggression among older elementary school children. In fact, the children who received no treatment decreased more in aggression than children who received the small-group peer-skills training (Level B) at this grade. The intervention participants did not change in aggression, whereas children in the control schools decreased in aggression. This argues against use of this type of intervention at this age for high-risk youths living in inner-city communities.

In both communities, we found the classroom intervention that combined teacher training for more effective behavior manage- ment and social-cognitive training of children improved relative level of academic achievement, when administered in the early grades. Although this effect was most pronounced in the general enhancement classroom intervention, in every early intervention condition, achievement test scores were relatively higher than among control children. The general enhancement component for each intervention condition seems to boost relative achievement. However, this effect was substantially smaller for the other two treatment conditions. Notably, the effect is one of maintaining or improving relative achievement while the control group increasingly drops off compared with national norms. The preventive benefit is to enable normal progress in a high-risk setting (Tolan et al., 1995). Repeating the intervention in the later grades supplements the effect of the early intervention, but initiating the intervention in later grades has little effect. None of these intervention effects varied by gender, although relative levels of aggression and achievement related to gender.

Several factors should be considered in understanding these results. First, the HLM analyses showed that in almost all cases schools contributed significant random variance. Within each community type, effects were related to school. The variance accounted for by schools may reflect characteristics of the schools themselves (e.g., school organization, principal effectiveness, and policy changes) or characteristics of the communities served by different schools. However, as these factors were not measured here, the specific source of this effect cannot be ascertained. Better understanding of school effects, including resources and impediments, is an important further step needed to help guide prevention efforts.

Second, school districts involved in our study were subject to a number of significant shifts in administrators, policies, and practices. In particular, schools in Chicago were under pressure to improve achievement and reduce social problems, to the extent of sometimes affecting their participation in intervention efforts. Similarly, there were also several changes in communities that could have appeared as random school effects. These factors render it particularly problematic to obtain a true no-treatment control group of school children and may explain some of the relative decrease in control group median aggression levels. Durlak (1998) discussed the "fantasy of untreated control groups," citing examples of intervention studies in which children in control schools received as many or more services than children in intervention schools. Although we made every effort to prevent control schools from implementing programs similar to ours, other psychological and social interventions were, in fact, implemented from time to time.

Our results also suggest that it is more important to examine what works for whom and under what conditions than trying to determine "what works." Our cognitive-ecological approach, which targets multiple components across multiple contexts, provides preventive benefits for aggression only for young children and only in communities that have more than the minimal economic resources and social-ecological supports (Sampson, Raudenbush, \& Earls, 1997). This can be understood in terms of "intervention fit," which can involve both individual and contextual characteristics (Tolan et al., 1995). In other words, the intervention must fit the needs of the children and the school and community based on their needs and resources (Elias, 1997). Similarly, in 
overwhelmed, inner-city schools and communities, carrying out such interventions may be difficult.

In terms of developmental timing, our findings lend support to the "earlier is better" dictum. Our findings are consistent with a number of other early intervention studies that have found preventive benefits during the kindergarten and early elementary years (e.g., Conduct Problems Prevention Research Group, 1999; Kellam et al., 1994). They are also consistent with developmental research that demonstrates the increasing stability of both behavior and cognition during the later elementary years (e.g., Huesmann \& Guerra, 1997). It is unclear whether earlier intervention would produce greater benefits. Possibly, beginning intervention during kindergarten rather than in the second grade would have enhanced the effects of our early intervention. Or, the greatest benefits may be achieved by beginning in kindergarten and continuing throughout elementary school (e.g., Conduct Problems Prevention Research Group, 1999). At least, it seems wise to give priority to programs in the early grades.

Notably, there were no Gender $\times$ Intervention Effect interactions, suggesting the impact was not differential for male and female participants. We did find, as do most others, that boys show higher levels of aggression, but the relative impact did not vary by gender, suggesting these approaches are equally useful across genders. Also, this study has one of the most ethnically diverse samples in a prevention trial to date, with strong representation of African American, non Hispanic White, and Latino youths and families. Thus, the potential generalization may be broad.

However, these conclusions are not without caveats. The present study suggests that to reduce aggression, programs must be comprehensive and, to reach most high-risk youths, be conducted in settings with sufficient resources and support. It may be that high-risk children in these communities simply require more extensive interventions than universal classroom efforts. Broadening the focus to integrate the universal effort with selective peer and family interventions seems to be valuable in non-inner-city communities for all high-risk youths and for the most high-risk youths in inner-city schools. This suggests that schools and parents need to be mobilized together to lower high-risk children's aggression.

Why did the full intervention have a negative effect generally when delivered to some young children in schools in the inner-city neighborhoods? It may be that in these schools, children and parents are already overtaxed and an intervention creates yet another demand that cannot be easily managed. These effects may also relate to community characteristics. In communities characterized by higher levels of economic disadvantage and community violence, strong reinforcement for some aggression may occur (e.g., such as a readiness to fight; Fagan \& Wilkinson, 1998). Parents and other influential adults may be more accepting of aggression in self-defense or to prevent threats (Sheidow, GormanSmith, Tolan, \& Henry, 2001). In such settings, peer and family meetings that try to modify approaches to social problems may raise but not resolve the difficult and complex issues of violence. Anecdotal comments from the peer and family groups lend support to this perspective. Children often commented that their parents told them to maintain the upper hand in violent or potentially violent situations. One should also remember that in communities with low resources, violence may be more ambiguous. Violent behavior can be seen as better than being victimized (Tolan, 2001).
The general enhancement plus small-group intervention appeared to lead to maintaining a high level of aggression when administered later in development in inner-city communities, whereas normally this level would decrease. This effect was observed in both communities. Reports of similar effects have recently emerged from other small-group intervention studies focused on delinquents (Dishion et al., 1999; Gottfredson \& Gottfredson, 1992). The present study extends this finding to children who were not previously identified as delinquent. Such effects have been attributed to groups of at-risk youths promoting negative norms and beliefs about aggression or delinquency: a form of "deviancy training" that provides reinforcement for aggression. This interpretation is also supported by research that shows that children's aggression changes over time depending on the norms of the other children in their classrooms (Henry et al., 2000). These results suggest great caution should be exercised about using small-group interventions that bring together children who are likely to endorse or reinforce aggression in response to perceived threats and provocation, particularly as they reach late elementary age.

Why did the general enhancement classroom intervention improve achievement in both communities? We have argued earlier that the interventions had some undesired effects in the lowresource communities because these schools may face greater problems and students may face different normative beliefs. Such factors, however, should interfere less with improving learning in class. This general enhancement intervention taught teachers effective behavior management techniques for creating a cooperative learning environment that promotes achievement. The results of this study suggest that such an intervention can aid academic achievement even if it does not have a direct impact on antisocial behavior outside the classroom.

Several noteworthy limitations should be considered in interpreting the implications of this study. First, and perhaps foremost, this study only included 16 schools with assignment at the school level. Although an advance in the HLM approach was developed to manage this limitation, this sample size can limit the reliability of estimates and may underestimate effects. It is clear that a test with an adequate number of schools would be advantageous. Unfortunately, with few exceptions, there has not been such a study to date, and the exceptions did not examine school level effects fully (Botvin, Epstein, Baker, Diaz, \& Ifill-Williams, 1997).

Second, as is an impediment to many longitudinal studies of interventions within high-risk communities, not all the participating schools were retained for the full study. Changes of school policy led to some loss, but some of the loss was due to the costs associated with retention. This suggests that future studies will need to plan for some school attrition and include adequate funding to maintain maximal retention. The approach taken here, of blocking and then limiting comparison with those sets of schools that still meet criteria for "random" assignment, may help manage both issues even with larger numbers.

In addition to school attrition, there was individual attrition. Although primarily due to mobility, there was some relation between loss and initial aggression score. One of the impositions of school-based assignment to condition is that as individuals move from a participating school, they cannot be considered for inclusion in intervention. This design imposition more closely approx- 
imates program access than does the artificial practice in many trials that follow and serve individuals once assigned, and it can lead to higher than usual attrition rates (Tolan \& Brown, 1998).

Interpreting results was also limited by some exigencies of the communities in which we worked. In particular, given current conditions, there is a substantial confound between the type of community and school (inner city vs. urban poor) and ethnic homogeneity. The poorest inner-city schools were almost exclusively African American. We could not distinguish ethnicity effects from school-community effects in this study. Given that this problem of economic and ethnic segregation still plagues most communities in the United States, this limitation may continue unless a complex and careful selection of exceptional communities is used.

Similarly, there is a confounding of place and type of community in this study. Aurora schools and communities not only differed in economic and other important indicators but were also located within a mid-sized city, whereas the inner-city schools of Chicago were located within a very large urban center. A study that could compare communities and their schools within one city or across similar cities could provide more clarification of how city size and community functioning contribute to the results.

Another caution relates to the transportability of this program. This was undertaken as an efficacy trial but one considering the exigencies of working in real urban poor schools and communities. Thus, the amount of resources applied is greater than may be available in normal service efforts. While this and other large prevention trials permit testing of key developmental and intervention issues, there may be a trade-off of transportability. Replication in practice may be difficult even with adequate consideration of practical issues that affect prevention efforts. These are important considerations in general that this study highlights. We expect these will become more prominent in subsequent trials as the relation of methodological and practical issues in prevention and community-based interventions is explored (Tolan, 1998).

Finally, we should note that schools selected for inclusion in random assignment had to apply and demonstrate strong support among faculty for the study and program. However, there is no evidence that these schools were atypical by any characteristic. Nevertheless, it may be that if applied to less enthusiastic schools, the effects would be smaller.

Although the results suggest the full intervention can affect the major behavioral predictor of later delinquency and violence in urban schools and communities with moderate resources and is promising, it is unclear if this finding will translate to lowered prevalence of delinquency and violence for the most high-risk youths in the inner city (Tremblay, Pagani-Kurtz, Masse, Vitaro, \& Pihl, 1995). The available studies to date provide conflicting direction about how proximal effects interact with developmental and ecological influences (Kellam \& Rebok, 1992). Some studies suggest likely diminution of initial benefits, whereas others suggest increasing benefit, and yet others suggest a more complex interaction between development and events and circumstances subsequent to the preventive exposure (Hawkins, Catalano, Kosterman, Abbott, \& Hill, 1999; Tremblay et al., 1995). For example, it may be that the relation of the proximal effects to ultimate prevalence levels depends on the school and community conditions that also seem to moderate initial impact. Tracing the longer term effects of the MACS intervention is one of the needed additional steps in evaluating its preventive benefits.

\section{References}

Aber, J. L., Jones, S. M., Brown, J. L., Chaudry, N., \& Samples, F. (1996). The evaluation of the Resolving Conflict Creatively Program: An overview. Preventive Medicine, 12, 82-90.

Achenbach, T. M. (1978). The child behavior profile: I. Boys aged 6-11. Journal of Consulting and Clinical Psychology, 46, 478-488.

Achenbach, T. M. (1991). Manual for the Teacher's Report Form and 1991 profile. Burlington, VT: Associates in Psychiatry.

Asher, S., Rose, A., Guerra, N. G., \& Tolan, P. H. (1993). Social tasks of inner city children. Unpublished manuscript, University of Illinois at Chicago.

Attar, B. K., Guerra, N. G., \& Tolan, P. H. (1994). Neighborhood disadvantage, stressful life events, and adjustment in urban elementary school children. Journal of Clinical Child Psychology, 23, 391-400.

Botvin, G. J., Epstein, J. A., Baker, E., Diaz, T., \& Ifill-Williams, M. (1997). School-based drug abuse prevention with inner-city minority youth. Journal of Child and Adolescent Substance Abuse, 6, 5-19.

Brown, C. H. (1993). Analyzing preventive trials with generalized additive models. American Journal of Community Psychology, 21, 635-664.

Bryk, A. S., Raudenbush, S. W., \& Congdon, R. (1996). HLM: Hierarchical linear and nonlinear modeling with the HLM/2L and HLM/3L programs. Chicago: Scientific Software International.

Chamberlain, P., \& Moore, K. J. (1998). Models of community treatment for serious offenders. In J. Crane (Ed.), Social programs that work (pp. 258-276). New York: Russell Sage Foundation.

Coie, J. D., Watt, N. F., West., S. G., Hawkins, J. D., Asarnow, J. R., Markman, H. J., Ramey, S. L., Shure, M. B., \& Long, B. (1993). The science of prevention. American Psychologist, 48, 1013-1022.

Cole, D., VanAcker, R., Grant, S., \& Henry, D. (1993). Metropolitan Area Child Study teacher collaborator manual. Unpublished manual, Metropolitan Area Child Study, Chicago.

Conduct Problems Prevention Research Group. (1999). Initial impact of the fast track prevention trial for conduct problems: I. The high-risk sample. Journal of Consulting and Clinical Psychology, 67, 631-647.

Crick, N. R., \& Dodge, K. A. (1994). A review and reformulation of social information processing mechanisms in children's adjustment. Psychological Bulletin, 115, 74-101.

CTB/McGraw-Hill. (1985). California Achievement Test. Montery, CA: Author.

Dishion, T. J., McCord, J., \& Poulin, F. (1999). When interventions harm. American Psychologist, 54, 755-764.

Dishion, T. J., Spracklen, K. M., Andrews, D. W., \& Patterson, G. R. (1996). Deviancy training in male adolescent friendships. Behavior Therapy, 27, 373-390.

Dunnett, C. W. (1955). A multiple comparison procedure for comparing several treatments with a control. Journal of the American Statistical Association, 50, 1096-1121.

Durlak, J. A. (1998). Why program implementation is important. Journal of Prevention and Intervention in the Community, 17, 5-18.

Eargle, A., Guerra, N. G., \& Tolan, P. (1994). Small-group treatment for children living in high violence neighborhoods. Journal of Child and Adolescent Group Therapy, 4, 229-243.

Elias, M. J. (1997). Reinterpreting dissemination of prevention programs as widespread implementation with effectiveness and fidelity. In R. P. Weissberg, T. P. Gullotta, R. L. Hampton, B. A. Ryan, \& G. A. Adams (Eds.), Establishing preventive services (pp. 253-289). Thousand Oaks, CA: Sage.

Elliott, D., Huizinga, D., \& Ageton, S. (1985). Explaining delinquency and drug use. Beverly Hills, CA: Sage.

Eron, L. D. (1987). The development of aggressive behavior from the 
perspective of a developing behaviorism. American Psychologist, 42, 435-442.

Eron, L. D., Laulicht, J. H., Walder, L. O., Farber, I. E., \& Spiegel, J. P. (1961). Application of role and learning theories to the study of the development of aggression in children. Psychological Reports, 9, 291334.

Eron, L. D., Walder, L. O., \& Lefkowitz, M. M. (1971). The learning of aggression in children. Boston: Little, Brown.

Fagan, J., \& Wilkinson, D. L. (1998). Social contexts and functions of adolescent violence. In D. S. Elliott \& B. A. Hamburg (Eds.), Violence in American schools: A new perspective (pp. 55-93). New York: Cambridge University Press.

Gottfredson, D. C. (1987). An evaluation of an organization development approach to reducing school disorder. Evaluation Review, 11, 739-763.

Gottfredson, D. C., \& Gottfredson, G. D. (1992). Theory-guided investigation: Three field experiments. In J. McCord \& R. Tremblay (Eds.), Preventing antisocial behavior: Interventions from birth through adolescence (pp. 311-329). New York: Guilford Press.

Greenberg, M. T., Kusche, C. A., Cook, E. T., \& Quamma, J. P. (1995). Promoting emotional competence in school-aged children: The effects of the PATHS curriculum. Development \& Psychopathology, 7, 117-136.

Greenwald, R., Hedges, L. V., \& Laine, R. D. (1996). The effect of school resources on student achievement. Review of Educational Research, 66, 361-396.

Grossman, D. C., Neckerman, J. H., Koepsell, T. D., Liu, P., Asher, K. N., Beland, K., Frey, K., \& Rivara, F. P. (1997). Effectiveness of a violence prevention curriculum among children in elementary school: A randomized control trial. Journal of the American Medical Association, 277, $1605-1611$

Guerra, N. G., Eron, L. D., Huesmann, L. R., Tolan, P. H., \& VanAcker, R. (1997). A cognitive-ecological approach to the prevention and mitigation of violence and aggression in inner-city youth. In P. Fry \& K. Bjorkqvist (Eds.), Cultural variation in conflict resolution: Alternatives for reducing violence (pp. 199-213). New York: Polonium.

Guerra, N. G., Huesmann, L. R., Tolan, P. H., VanAcker, R., \& Eron, L. D. (1995). Stressful events and individual beliefs as correlates of economic disadvantage and aggression among urban children. Journal of Consulting and Clinical Psychology 63, 518-528.

Guerra, N. G., \& Moore, A. (1991). Yes I can manual. Unpublished manual, Metropolitan Area Child Study, Chicago.

Guerra, N. G., Tolan, P. H., Huesmann, L. R., VanAcker, R., Eron, L. D., \& Henry, D. (1993). Prevention of antisocial behavior in inner city and urban children (National Institute of Mental Health Research Grant No. MH-48034). Available from P. Tolan, Institute for Juvenile Research, University of Illinois at Chicago, 840 Southwood Street, Chicago, IL 60612.

Hanish, L., \& Tolan, P. H. (in press). Patterns of response to a family aggression prevention program. Journal of Marriage and Family Therapy.

Hawkins, J. D., Catalano, R. F., Kosterman, R., Abbott, R., \& Hill, K. G. (1999). Preventing adolescent health-risk behaviors by strengthening protection during childhood. Archives of Pediatrics and Adolescent Medicine, 153, 226-324.

Hawkins, J. D., Von Cleve, E., \& Catalano, R. F. (1991). Reducing early childhood aggression: Results of a primary prevention program. Journal of the American Academy of Child and Adolescent Psychiatry, 30, 208-217.

Henggeler, S. W., Cunningham, B. P., Pickrel, S. G., Schoenwald, S. K., \& Brondino, M. J. (1996). Multisystemic therapy: An effective violence prevention approach for serious juvenile offenders. Journal of Adolescence, 19, 47-61.

Henggeler, S. W., Rodick, J. J., Borden, C. M., Chanson, C. L., Watts, S. M., \& Urea, J. R. (1986). Multisystemic treatment of juvenile offend- ers: Effects on antisocial behavior and family interaction. Developmental Psychology, 22, 132-141.

Henry, D., Guerra, N. G., Huesmann, L. R., Tolan, P. H., VanAcker, R., \& Eron, L. D. (2000). Normative influences on aggression in urban elementary school classrooms. American Journal of Community Psychology, 28, 59-81.

Hieronymous, N. A., Hoover, H. D., \& Linquist, E. F. (1986). Iowa Tests of Basic Skills. Chicago: Riverside.

Huesmann, L. R. (1988). An information-processing model for the development of aggression. Aggressive Behavior, 14, 13-24.

Huesmann, L. R. (1998). The role of social information processing and cognitive schemas in the acquisition and maintenance of habitual aggressive behavior. In R. G. Geen \& E. Donnerstein (Eds.), Human aggression: Theories, research, and implications for policy (pp. 73109). New York: Academic Press.

Huesmann, L. R., \& Eron, L. D. (1986). Television and the aggressive child. Hillsdale, NJ: Erlbaum.

Huesmann, L. R., Eron, L. D., Guerra, N. G., \& Crawshaw, V. B. (1994). Measuring children's aggression with teachers' predictions of peer nominations. Psychological Assessment, 6, 329-336.

Huesmann, L. R., Eron, L. D., Lefkowitz, M. M., \& Walder, L. O. (1984). Stability of aggression over time and generations. Developmental Psychology, 20, 1120-1134.

Huesmann, L. R., Eron, L. D., \& Yarmel, P. W. (1987). Intellectual functioning and aggression. Journal of Personality and Social Psychology, 52, 232-240.

Huesmann, L. R., \& Guerra, N. G. (1997). Children's normative beliefs about aggression and aggressive behavior. Journal of Personality and Social Psychology, 72, 408-419.

Illinois State Board of Education. (1999). School report card data for Illinois schools. Springfield, IL: Author.

Kazdin, A. E. (1987). Treatment of antisocial behavior in children: Current status and future directions. Psychological Bulletin, 102, 187-203.

Kellam, S. G., \& Rebok, G. W. (1992). Building developmental and etiological theory through epidemiologically based preventive intervention trials. In J. McCord \& R. E. Tremblay (Eds.), Preventing antisocial behavior: Interventions from birth through adolescence, (pp. 162-195). New York: Guilford Press.

Kellam, S. G., Rebok, G. W., Ialongo, N., \& Mayer, L. S. (1994). The course and malleability of aggressive behavior from early first grade into middle school: Results of a developmental epidemiologically-based preventive trial. Journal of Child Psychology and Psychiatry and Allied Disciplines, 35, 259-281.

Kendall, P. C., Marrs-Garcia, A., Nath, S. R., \& Sheldrick, R. C. (1999). Normative comparisons for the evaluation of clinical significance. Journal of Consulting and Clinical Psychology, 67, 285-299.

Lefkowitz, M. M., Eron, L. D., Walder, L. O., \& Huesmann, L. R. (1977). Growing up to be violent: A longitudinal study of the development of aggression. New York: Pergamon.

Little, R. J., \& Rubin, D. B. (1987). Statistical analysis with missing data. New York: Wiley.

Little, R. J., \& Yau, L. H. Y. (1998). Statistical techniques for analyzing data for prevention trials: Treatment of no-shows using Rubin's causal model. Psychological Methods, 3, 147-159.

McCord, J., Tremblay, R. E., Vitaro, F., \& Desmarais-Gervais, L. (1994). Boys' disruptive behaviour, school adjustment, and delinquency: The Montreal prevention experiment. International Journal of Behavioral Development, 17, 739-752.

McLoyd, V. (1990). The impact of economic hardship on black families and children: Psychological distress, parenting, and socioemotional development. Child Development, 61, 311-346.

Olds, D. (1990). Can home visitation improve the health of women and children at environmental risk? Pediatrics, 86, 108-116.

Pepler, D. J., King, G., \& Byrd, W. (1991). A social-cognitively based 
social skills training for aggressive children. In D. J. Pepler \& K. H. Rubin (Eds.), The development and treatment of childhood aggression (pp. 361-379). Hillsdale, NJ: Erlbaum.

Raudenbush, S., \& Congdon, R. (1999). An HLM program for use with multiply imputed criterion and predictor variables (Tech. Rep.). Ann Arbor: University of Michigan.

Reid, J. B., Eddy, J. M., Fetrow, R. A., \& Stoolmiller, M. (1999). Description and immediate impacts of a preventive intervention for conduct problems. American Journal of Community Psychology, 27, 483-517.

Riverside Publishing Co. (1993). La Prueba Riverside de Realizacion, Secunda Edicion [The path to success]. Chicago: Author.

Rubin, K. H., Bream, L. A., \& Rose-Krasnor, L. (1991). Social problem solving and aggression in childhood. In D. J. Pepler \& K. H. Rubin (Eds.), The development and treatment of childhood aggression (pp. 219-248). Hillsdale, NJ: Erlbaum.

Salvia, J., \& Yesseldyke, J. E. (1991). Assessment. New York: HoughtonMifflin.

Sampson, R. J., Raudenbush, S. W., \& Earls, F. (1997). Neighborhoods and violent crime: A multilevel study of collective efficacy. Science, 277, 918-924.

Shair, H. N. (Ed.). (1991). Development and psychobiology: New methods and changing concepts. New York: Oxford University Press.

Sheidow, A. J., Gorman-Smith, D., Tolan, P. H., \& Henry, D. (2001). Family and community characteristics: Risk factors for violence exposure in inner-city youth. Manuscript submitted for publication.

Spindler, A., \& Huesmann, L. R. (1999). Combining peer and teacher reports to measure children's aggressive behavior. Unpublished manuscript.

Tolan, P. H. (1998). Community and prevention research. In P. Kendall, J. Butcher, \& G. Holmbeck (Eds.), Handbook of research methods in clinical psychology (2nd ed., pp. 403-418). New York: Wiley.

Tolan, P. H. (2001). Emerging themes and challenges in understanding youth violence involvement. Journal of Clinical Child Psychology, 30, 233-239.

Tolan, P. H., \& Brown, C. H. (1998). Methods for evaluating intervention and prevention eforts. In P. K. Trickett \& C. J. Schellenbach (Eds.), Violence against children in the family and the community (pp. 439464). Washington, DC: American Psychological Association.

Tolan, P. H., Florsheim, P., McKay, M. M., \& Kohner, K. (1993). Metropolitan Area Child Study Family Intervention Manual. Unpublished manual, Metropolitan Area Child Study, Chicago.

Tolan, P. H., \& Guerra, N. G. (1994). Prevention of delinquency: Current status and issues. Applied and Preventive Psychology, 3, 251-273.
Tolan, P. H., Guerra, N. G., \& Kendall, P. (1995). A developmentalecological perspective on antisocial behavior in children and adolescents. Journal of Consulting and Clinical Psychology, 63, 579-584.

Tolan, P. H., Hanish, L., McKay, M., \& Dickey, M. (in press). Evaluating process in child and family interventions: Prevention of aggression as an example. Journal of Family Psychology.

Tolan, P. H., \& Henry, D. (1996). Patterns of psychopathology among urban poor children: Comorbidity and aggression effects. Journal of Consulting and Clinical Psychology, 64, 1094-1099.

Tolan, P. H., \& McKay, M. (1996). Preventing serious antisocial behavior in inner-city children: An empirically based family intervention program. Family Relations: Journal of Applied Family and Child Studies, 45, 145-155.

Tremblay, R. E., Pagani-Kurtz, L., Masse, L. C., Vitaro, F., \& Pihl, R. O. (1995). A bimodal preventive intervention for disruptive kindergarten boys: Its impact through mid-adolescence. Journal of Consulting and Clinical Psychology, 63, 560-568.

U.S. Bureau of the Census. (1993). Statistical abstract of the United States. Washington, DC: U.S. Government Printing Office.

Webster-Stratton, C. (1990). Long-term follow-up of families with young conduct problem children: From preschool to grade school. Journal of Clinical Child Psychology, 19, 144-149.

Weissberg, R. P., Gesten, E. L., Rapkin, B. D., Cowen, E. L., Davidson, E., de Apodaca, R. F., \& McKim, B. J. (1981). The evaluation of a social problem-solving training program for suburban and inner-city third grade children. Journal of Consulting and Clinical Psychology, 49, 251-261.

Weissberg, R. P., \& Greenberg, M. T. (1997). School and community competence-enhancement and prevention programs. In I. E. Sigel \& K. A. Renninger (Eds.), Handbook of child psychology: Vol. 6: Child psychology in practice (pp. 1-85). New York: Wiley.

Wilson, W. J. (1987). The truly disadvantaged: The inner city, the underclass, and public policy. Chicago: University of Chicago Press.

Yoshikawa, H. (1994). Prevention as cumulative protection: Effects of early family support and education on chronic delinquency and its risks. Psychological Bulletin, 115, 28-54.

Zigler, E., Taussig, C., \& Black, K. (1992). Early childhood intervention: A promising preventive for juvenile delinquency. American Psychologist, 47, 997-1006.

Received February 4, 2000

Revision received August 1, 2001

Accepted August 7, 2001 